\title{
The Tale of Protein Lysine Acetylation in the Cytoplasm
}

\author{
Karin Sadoul, ${ }^{1}$ Jin Wang, ${ }^{1,2}$ Boubou Diagouraga, ${ }^{1}$ and Saadi Khochbin ${ }^{1}$ \\ ${ }^{1}$ INSERM, U823, Institut Albert Bonniot, Université Joseph Fourier Grenoble 1, 38700 Grenoble, France \\ ${ }^{2}$ State Key Laboratory of Medical Genomics, Department of Hematology, Ruijin Hospital, Shanghai Institute of Hematology, \\ Shanghai Jiao Tong University School of Medicine, Shanghai 200025, China \\ Correspondence should be addressed to Karin Sadoul, karin.sadoul@ujf-grenoble.fr
}

Received 20 July 2010; Accepted 29 September 2010

Academic Editor: Patrick Matthias

Copyright () 2011 Karin Sadoul et al. This is an open access article distributed under the Creative Commons Attribution License, which permits unrestricted use, distribution, and reproduction in any medium, provided the original work is properly cited.

Reversible posttranslational modification of internal lysines in many cellular or viral proteins is now emerging as part of critical signalling processes controlling a variety of cellular functions beyond chromatin and transcription. This paper aims at demonstrating the role of lysine acetylation in the cytoplasm driving and coordinating key events such as cytoskeleton dynamics, intracellular trafficking, vesicle fusion, metabolism, and stress response.

\section{Introduction}

The story of cytoplasmic protein lysine acetylation begins long after the discovery of posttranslational acetylation of histones in the sixties [1]. In fact only in 1985 tubulin was described as the first acetylated cytoplasmic protein $[2,3]$. Since then numerous other cytoplasmic proteins have been found acetylated. The first global proteomic study on acetylated proteins describes 37 acetylated proteins in the cytoplasmic fraction of Hela cells and 133 in mouse liver mitochondria [4]. In another study about 250 acetylated proteins, presumably localized in the cytoplasm, have been identified [5].

Lysine $(\mathrm{K})$ acetylation is catalysed by a lysine acetyltransferase (KAT) formerly called histone acetyltransferase (HAT) (for new nomenclature see Allis et al. [6]), which transfers the acetyl-group of acetyl-CoA to the epsilon-amino group of an internal lysine residue. The reverse reaction is accomplished by deacetylases, which can be divided into several classes. The class I, IIa, IIb, and IV enzymes are zinc dependant, whereas members of the class III family (also called sirtuins) use NAD+ as a cofactor for the deacetylation reaction.

The high number of acetylated proteins present in the cytoplasm points to a critical role for this posttranslational modification in the regulation of cytoplasmic events. In this paper we will focus on selected examples illustrating the role of reversible acetylation in the cytoplasm and we will mention some proteins, identified by proteomic approaches as being acetylated, when it could be important in the context of the discussed cellular processes. We will also provide an overview on what is known about the cytoplasmic localisation of the enzymes implicated in lysine (de)acetylation.

\section{Cytoplasmic Localisation of KATs and HDACs}

2.1. KATs. Most of the extensively characterised acetyltransferases are known as nuclear enzymes (see Table 1 for overview). Even Hat1, the first identified acetyltransferase, is predominantly localized in the nucleus, although it has been characterized as a type B acetyltransferase which refers to its role in the cytoplasm where it acetylates newly synthesised histones [7-9]. Under some circumstances, like early during development or in colorectal tumors, the cytoplasmic fraction of Hat1 increases $[10,11]$. In addition, it has recently been shown that two different isoforms of Hat 1 are expressed in keratinocytes, which differ in their cellular localisation [12].

Although acetyltransferases are considered mostly nuclear, an increasing number of studies reports on their nucleocytoplasmic transport. For instance PCAF and Gcn5 become phosphorylated following growth factor receptor signalling, which induces their translocation to the nucleus [13]. The cellular localisation of PCAF is not only regulated by phosphorylation. In fact PCAF can autoacetylate lysine 
residues within its nuclear localisation signal (NLS) and deacetylation of these lysine residues leads to cytoplasmic accumulation of PCAF [14]. CBP and p300 behave almost like Hatl since, during oocyte maturation, they are first found in the cytoplasm before being imported into the nucleus [15]. Furthermore, similar to Hat1, p300 is found in the cytoplasm in breast carcinomas but not in the adjacent normal mammary gland [16]. Both nuclear localisation and nuclear export signals have been found in Tip60, a member of the MYST family of acetyltransferases. Tip60 can be recruited to the plasma membrane by the amyloid precursor protein, which induces its phosphorylation and subsequent translocation to the nucleus [17]. In addition Tip60 appears in two splice variants. Whereas the longer isoform is essentially found in the nucleus, the shorter form, Tip60 beta (also called PLIP), missing exon 5, is located in both the cytoplasm and the nucleus and interacts with cytosolic phospholipase A2 [18, 19]. The acetyltransferase ATF2 also has nuclear localisation and export signals and is able to shuttle between the nucleus and the cytoplasm. Heterodimerisation with c-Jun in the nucleus is necessary to retain ATF2 in the nuclear compartment [20].

The most astonishing fact is that, although tubulin was the first acetylated protein described in the cytoplasm [2,3] and a tubulin acetyltransferase activity had already been purified and characterised in 1986 [21], the scientific community had to wait until 2009 to put a name on an enzyme able to acetylate $\alpha$-tubulin. In fact the acetyltransferase Elp3, which is the catalytic subunit of the transcriptional elongator complex, was found able to acetylate tubulin, which is essential for the maturation of cortical neurons [22]. The role of Elp3 as a tubulin acetyltransferase important for neuronal development has been confirmed in a genetic RNAi suppression screen for regulators of $\alpha$-tubulin acetylation using the nematode Caenorhabditis elegans [23]. Besides its role in tubulin acetylation, Elp3 has been implicated in the regulation of other processes outside the nucleus such as stress signalling, tRNA modification, exocytosis and actin dynamics [24-28]. A study by Esberg et al., however, questions the role of Elp3 as an acetyltransferase since various effects observed in Elp3 deficient cells could be attributed to its role in tRNA modifications and more specifically to the absence of wobble uridine modified lysine and glutamine tRNA species $[29,30]$. A recently published paper describes Gcn 5 as another acetyltransferase, capable of acetylating $\alpha$-tubulin after its recruitment to microtubules via a cytoplasmic proteolytic fragment of myc [31]. Importantly, another recent paper identifies Mec-17, a Gcn5related protein, as a major alpha tubulin acetyltransferase [32]. Finally, two reports suggest that enzymes having Nacetyltransferase activity could also acetylate internal lysine residues and contribute to tubulin acetylation $[33,34]$.

2.2. HDACs. Compared to the Hat families there are by far more examples of deacetylases located in the cytoplasm (see Table 2 for list of HDACs). Even members of the type I family of deacetylases, which in the past have been considered as strictly nuclear proteins, can be found in the cytoplasm. For instance HDAC1 is a nuclear enzyme which, under pathological situations, is exported via CRM1 into the cytoplasm where it binds to kinesin motors, hindering cargo transport [35]. HDAC3, another type I deacetylase, is found in the nucleus and the cytoplasm and has both nuclear export as well as nuclear localisation signals [36]. It is retained in the cytoplasm via its interaction with IkappaBalpha [37] until TNF-alpha signalling leads to the degradation of this binding partner [38]. Furthermore HDAC3 can associate with the plasma membrane where it is phosphorylated by src thereby increasing its activity [39]. Surprisingly, in contrast to the other class I enzymes which are more nuclear, HDAC8 is essentially in the cytoplasm where it associates with smooth muscle alpha actin to regulate cell contractility $[40,41]$.

Class IIa deacetylases (4, 5, 7 and 9) [42] are known to shuttle between the nucleus and the cytoplasm $[43,44]$. HDAC7 is the only member of this family reported to be present also in mitochondria; it leaves mitochondria and the nucleus to accumulate in the cytoplasm after initiation of apoptosis [45]. All class IIa members have nuclear localisation signals and binding sites for proteins of the 143-3 family. An important regulatory mechanism relies on the phosphorylation of these 14-3-3 binding sites inducing the interaction with 14-3-3 proteins and subsequent accumulation in the cytoplasm. Cytoplasmic accumulation has been attributed to 14-3-3-mediated CRM1- dependant nuclear export but two publications have shown more recently that phosphorylation can target the NLS and that the deacetylases are retained in the cytoplasm after binding of 14-3-3 to the phosphorylated NLS and disruption of the nuclear import $[46,47]$. Independent of its phosphorylation status, the nuclear export of HDAC4 is regulated by oxidation of two of its cystein residues resulting in an intramolecular disulfide bridge, whose reduction inhibits nuclear export [48]. HDAC7 is another example of a class IIa enzyme, which can be exported from the nucleus independently of its phosphorylation status and 14-3-3 binding [49].

The translocation of type I and IIa HDACs into the cytoplasm in all the examples mentioned above (except HDAC8) is generally considered as a regulatory mechanism, which serves to reduce their action in the nucleus and so far cytoplasmic substrates have only been found for HDAC4 (as discussed below).

The most extensively studied cytoplasmic deacetylase is the type IIb enzyme HDAC6, which has several cytoplasmic substrates, including tubulin [50-52], cortactin [53], Hsp90 [54-57], $\beta$-catenin [58], and peroxiredoxin [59]. Although it bears intrinsic nuclear import and export signals, HDAC6 is almost exclusively localised in the cytoplasm [60, 61], where its actions underlie multiple regulatory processes. One way to regulate its action is to change its localisation within the cytoplasm. As mentioned below HDAC6 is translocated together with Hsp90 and Rac1 to membrane ruffles after PDGF stimulation where it influences actin dynamics [62]. Tubulin deacetylation by HDAC6 can be prevented by $\mathrm{Cbl}$, due to competitive binding to $\beta$-tubulin [63]. Another way influencing its activity is the binding to various partner proteins either directly or indirectly. An example of an indirect interaction essential for HDAC6 activity is the formation 
TABLE 1: Lysine (K) acetyltransferases.

\begin{tabular}{|c|c|c|c|c|c|}
\hline New Name & $\begin{array}{l}\text { Former name } \\
\text { human }\end{array}$ & $\begin{array}{c}\text { Former name D. } \\
\text { melanogaster }\end{array}$ & $\begin{array}{l}\text { Former name } \\
\text { S. cerevisiae }\end{array}$ & $\begin{array}{c}\text { Former name S. } \\
\text { pombe }\end{array}$ & HAT complexes \\
\hline \multicolumn{6}{|c|}{ GNAT family } \\
\hline KAT1 & HAT1 & CG2051 & Hat1 & Hat1/Hag603 & HAT-B \\
\hline KAT2 & & dGCN5/PCAF & Gcn5 & Gcn 5 & SAGA, ADA, ATAC \\
\hline KAT2A & hGCN5 & & & & STAGA, TFTC \\
\hline KAT2B & PCAF & & & & PCAF complex \\
\hline \multirow[t]{2}{*}{ KAT9 } & ELP3 & dELP3/CG15433 & Elp3 & Elp3 & $\begin{array}{l}\text { Elongator for RNA } \\
\text { polymerase II }\end{array}$ \\
\hline & HsMEC-17 & & & & \\
\hline \multicolumn{6}{|c|}{ p300/CBP family } \\
\hline KAT3 & & $\mathrm{dCBP} / \mathrm{NEJ}$ & & & \\
\hline KAT3A & $\mathrm{CBP}$ & & & & \\
\hline KAT3B & P300 & & & & \\
\hline \multicolumn{6}{|c|}{ MYST family } \\
\hline KAT5 & TIP60/PLIP & dTIP60 & Esa1 & Mst1 & $\mathrm{NuA} 4$ \\
\hline KAT6 & & (CG1894) & Sas3 & (Mst2) & $\mathrm{NuA} 3$ \\
\hline KAT6A & MOZ/MYST3 & & & & \\
\hline KAT6B & MORF/MYST4 & & & & \\
\hline KAT7 & HBO1/MYST2 & & & (Mst2) & \\
\hline KAT8 & hMOF/MYST1 & dMOF (CG1894) & Sas2 & (Mst2) & MSL complex \\
\hline \multicolumn{6}{|c|}{$\begin{array}{l}\text { nuclear receptor } \\
\text { coactivators }\end{array}$} \\
\hline KAT13A & SRC-1 & & & & \\
\hline \multirow[t]{5}{*}{ KAT13B } & ACTR & & & & \\
\hline & SRC-3 & & & & \\
\hline & TIF-2 & & & & \\
\hline & GRIP1 & & & & \\
\hline & ATF-2 & & & & \\
\hline \multicolumn{6}{|l|}{ Divers } \\
\hline KAT4 & TAF1 (TAFII250) & dTAF1 & Taf1 & Taf1 & TFIID \\
\hline KAT10 & & & Hap2 & & \\
\hline KAT11 & & & Rtt109 & & \\
\hline KAT12 & TFIIIC90 & & & & \\
\hline KAT13C & P160 & & & & \\
\hline KAT13D & CLOCK & & & & \\
\hline
\end{tabular}

of a tripartite complex composed of the farnesyltransferase, HDAC6, and microtubules. Disruption of the complex by $\mathrm{KO}$ of the alpha subunit of the farnesyltransferase or by an inhibitor of this enzyme leads to enhanced tubulin acetylation [64]. BBIP10, a protein essential for primary cilia formation also binds to and inhibits HDAC6, but so far it is not clear whether this interaction is direct or not [65]. An example of a direct interaction is the binding of Dia2 to one of the two deacetylase domains of HDAC6, which leads to activation of HDAC6 in osteoclasts [66]. Two other examples are the microtubule-associated protein tau and the tubulin polymerisation promoting protein TPPP/p25, which can bind to HDAC6 and inhibit its activity leading to a subsequent increase in microtubule acetylation [6769]. Ilp45 (a newly discovered protein) as well as CYLD, a deubiquitinating enzyme, can both inhibit HDAC6 by direct binding to the deacetylase domains of HDAC6, which in the case of Ilp45 will also lead to HDAC6 degradation $[70,71]$. A third way to regulate HDAC6's activity is by its posttranslational modification. It has been shown for instance that HDAC6 interacts with EGFR and is phosphorylated by EGFR at Tyr570 after ligand-induced receptor activation [72]. This reduces HDAC6 activity leading to tubulin acetylation and accelerated delivery of endocytosed EGFR to lysosomes. In contrast Aurora A, a mitotic ser/thr kinase, phosphorylates HDAC6 leading to its activation 


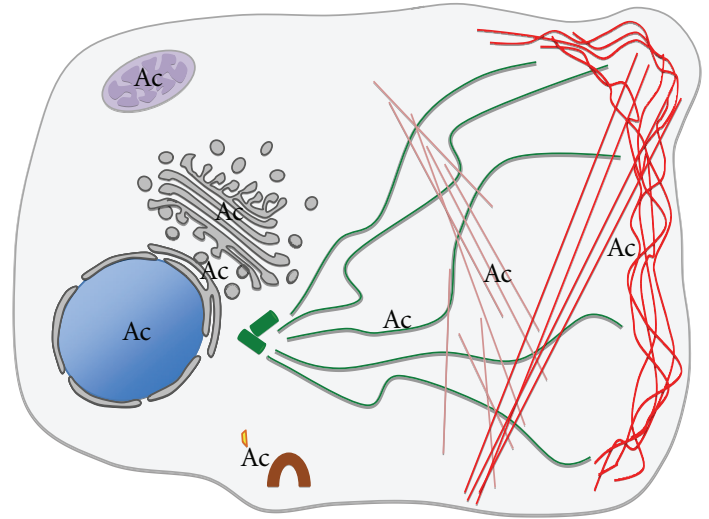

(a)

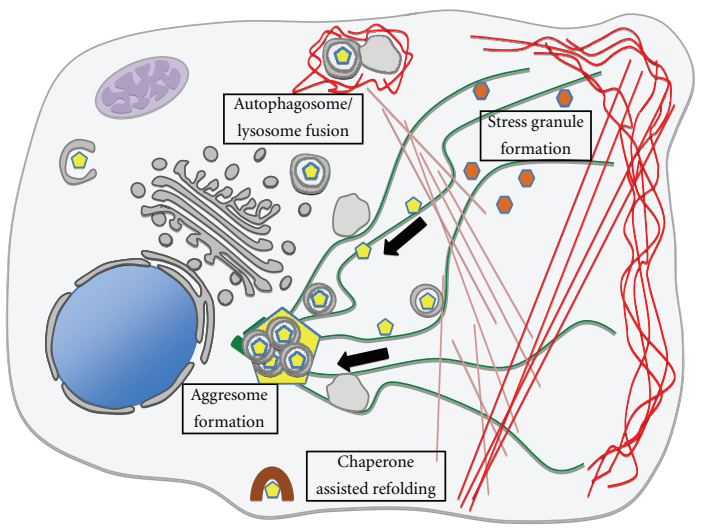

(c)

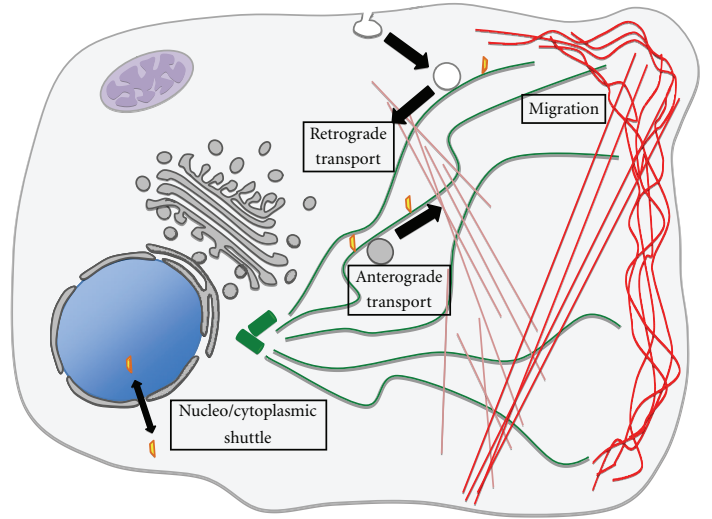

(b)

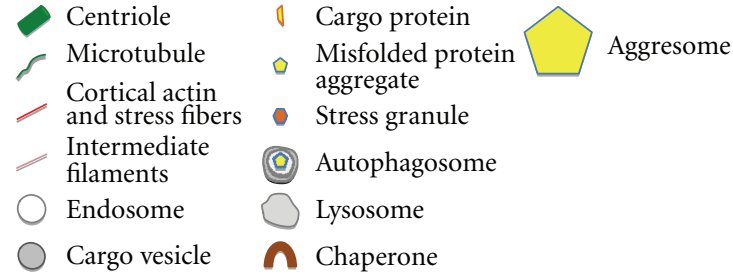

FIGURE 1: Schematic overview of cytoplasmic mechanisms regulated by acetylation. (a) Localisation of acetylation events within a cell. Indicated are individual acetylated proteins and cytoskeletal structures (cortical actin and actin stress fibers, microtubules, intermediate filaments) as well as organelles (nucleus, mitochondria, ER, ERGIC, golgi) in which acetylation and deacetylation events take place. (b) Involvement of reversible acetylation in the regulation of various cytoplasmic processes, including cell migration following cytoskeleton remodelling, individual protein transport as well as vesicular transport and nucleocytoplasmic shuttling of proteins. (c) Regulation of stress response and cytoplasmic cleanup systems by various acetylation/deacetylation events.

resulting in tubulin deacetylation and resorption of primary cilia in human retinal cells [73]. In this context it is worth mentioning that HDAC6 (as well as other HDACs) can be found in complexes together with phosphatases and both enzymes are active under these conditions [74]. HDAC6 activity, besides being regulated by phosphorylation, can also be reduced by $\mathrm{p} 300$-mediated acetylation [75]. In addition to its deacetylase function, HDAC6 has other important cellular tasks, such as cargo transport by binding to the dynein and kinesin motor complexes, or binding to mono and polyubiquitin, which is necessary for aggresome formation and induction of quality control autophagy (QC-autophagy) (for review see $[76,77]$ ).

HDAC10, the other class IIb enzyme, is present in the cytoplasm and the nucleus and, in contrast to the class IIa family members, is not exported through a CRM1-mediated transport mechanism [78-81]. Finally HDAC11, the only type IV deacetylase, is essentially a nuclear enzyme but can be found in the cytoplasm in latent HIV infected cells $[82,83]$.

The sirtuin or class III family of deacetylases are a functionally distinct family for two reasons. First they depend on the cofactor NAD+ for their activity, and second they do not release free acetate after hydrolyses of the acetyl group but rather transfer it onto ADP-ribose. In mammals, seven sirtuins have been described (Sirt1-7) [84]. Only Sirt1, Sirt2, and Sirt3 have a true deacetylase activity all the others have only ADP-ribosyltransferase activity. At least, this was considered the truth until it was observed that Sirt6 could deacetylate lysine 9 of histone H3 [85]. No cytoplasmic localisation, however, has been observed for Sirt6; we will therefore focus only on Sirt1-3 [86].

Sirt1 has both a nuclear localisation and a CRM1dependent export signal and, in most cells, it is present both in the nucleus and the cytoplasm [87]. Upon induction of neural differentiation it is transiently transported into the nucleus but for NGF-induced neurite outgrowth it has to be present in the cytoplasm $[88,89]$. As discussed below, Sirt1 has important roles in the cytoplasm linked to autophagy and cell migration via deacetylation of cortactin [90, 91].

Sirt2 is almost only localised in the cytoplasm due to an active CRM1-dependent export mechanism [92]. It has been implicated in tubulin deacetylation [93] and seems to 
TABle 2: Lysine (K) deacetylases.

\begin{tabular}{|c|c|c|}
\hline Name & Localisation & $\begin{array}{l}\text { Cytoplasmic } \\
\text { substrates }\end{array}$ \\
\hline \multicolumn{3}{|l|}{ Class I } \\
\hline HDAC1 & mainly nucleus & \\
\hline HDAC2 & nucleus & \\
\hline HDAC3 & mainly nucleus/cytoplasm & \\
\hline HDAC8 & mainly cytoplasm & \\
\hline \multicolumn{3}{|l|}{ class IIa } \\
\hline HDAC4 & cytoplasm/nucleus & $\begin{array}{l}\text { MLP, } \\
\text { DNAJB8 }\end{array}$ \\
\hline HDAC5 & cytoplasm/nucleus & \\
\hline HDAC7 & cytoplasm/mitochondria/nucleus & \\
\hline HDAC9 & cytoplasm/nucleus & \\
\hline \multicolumn{3}{|l|}{ Class IIb } \\
\hline HDAC6 & cytoplasm & $\begin{array}{l}\text { tubulin, } \\
\text { cortactin, } \\
\text { Hsp90, } \\
\beta \text {-catenin, } \\
\text { peroxiredoxin }\end{array}$ \\
\hline HDAC10 & cytoplasm/nucleus & \\
\hline \multicolumn{3}{|l|}{ Class IV } \\
\hline HDAC11 & mainly nucleus & \\
\hline \multicolumn{3}{|l|}{$\begin{array}{l}\text { Class } \\
\text { III(sirtuins) } \\
\end{array}$} \\
\hline $\operatorname{sirt1}$ & cytoplasm/nucleus & $\begin{array}{l}\text { cortactin, } \\
\text { Atg5, Atg7, } \\
\text { Atg8 }\end{array}$ \\
\hline sirt2 & cytoplasm & $\begin{array}{l}\text { tubulin, } \\
\text { cortactin? }\end{array}$ \\
\hline $\operatorname{sirt3}$ & mitochondria/long form cytoplasm & \\
\hline $\operatorname{sirt} 4$ & mitochondria & \\
\hline sirt5 & mitochondria & \\
\hline sirt6 & nucleus & \\
\hline sirt7 & nucleus & \\
\hline
\end{tabular}

deacetylate tubulin especially under certain circumstances, for instance during mitosis to regulate mitotic microtubule dynamics [94] or during oligodendrocyte differentiation [95]. It was suggested that Sirt2 inhibition could reduce alpha synuclein toxicity in Parkinson disease, but the molecular interplay has not been identified $[96,97]$.

Finally, Sirt3 is known as a mitochondrial enzyme (for a detailed review see [84]), but a long form of Sirt3 partially localised in the cytoplasm has been recently described [98].

At last, it is worth mentioning that quite a few nuclear and cytoplasmic acetylated proteins are targeted by both, class I/II as well as class III, deacetylases as for instance histones [99], tubulin [50-52, 93], Ku70 [98, 100], p53 $[101,102]$, and cortactin $[53,91]$. For most of these examples it is not clear whether HDACs of different classes show a preference for particular acetylated lysine residues in these proteins. Actually, motif preferences for lysine acetylation only start to emerge. The local sequence context around acetylated lysine residues in cytoplasmic proteins appears to be different from that of histones but similar to that of other nuclear proteins. Furthermore mitochondrial acetylation motifs differ from acetylation sites found in both histones and other nuclear/cytoplasmic proteins $[4,5]$. In spite of these advances a precise consensus sequence for the substrate specificity of different Kats or HDACs has yet to be defined.

\section{Functional Implications of Cytoplasmic Lysine Acetylation}

3.1. Regulation of the Cytoskeleton. Since the cytoskeleton is involved in many cytoplasmic processes, we will start by describing what is known about the regulatory effect of acetylation on the three main types of cytoskeletal components, namely, actin filaments, microtubules, and intermediate filaments (Figures 1(a) and 1(b)).

3.1.1. Actin Filaments. The globular monomeric form of actin (G-actin) polymerises to form a double helix (filamentous or F-actin), which can then be bundled into stress fibers. There are three major isoforms of actin. Beta and gamma actin form the stress fibers are important for cell shape and cell movement. Alpha actin constitutes the microfilaments in muscle cells, which together with myosin assures the traction forces necessary not only for muscle contraction but also for cytoplasmic streaming in nonmuscle cells. Using proteomic approaches it has been shown that all three actin isoforms can be acetylated $[4,5]$ and acetylation of lysine 61 in gamma actin may result in stabilisation of actin stress fibers [4]. Not only actin itself but also several regulatory proteins of the actin cytoskeleton are modified by acetylation. For instance six out of the seven subunits of the Arp2/3 complex, which is important for actin nucleation, are acetylated [5]. Cortactin binds to F-actin in the cell cortex and can recruit the Arp $2 / 3$ complex to the cortical actin cytoskeleton when it has been activated by phosphorylation. But phosphorylation is not the only regulatory modification of cortactin. It has been shown that cortactin can be acetylated by p300 or PCAF on nine different lysine residues present in its central repeat domain $[53,91]$. When acetylated its translocation to the cell periphery is inhibited and its actin binding capacity reduced. This leads to diminished actin dynamics at the cell periphery and thus to altered cell motility. Deacetylation of cortactin is mediated via HDAC6 and Sirt1 (maybe also Sirt2), which may act in cooperation to induce cell migration $[53,91]$. In fact the actin cytoskeleton is essential for cell migration since it is necessary for the formation of membrane ruffles or lamellipodia, filopodia, and actin stress fibers, which reflect different dynamic states of the actin cytoskeleton. Actin dynamics is also regulated by small GTPases of the Rho family. A simplified general scheme implicates RhoA in stress fiber formation, Racl in lamellipodia and cdc42 in filopodia formation. The activation of these G-proteins in turn depends on the action of GDIs (GDP dissociation inhibitors), GAPs (GTPase-activating proteins), and GEFs (GDP/GTP exchange factors). It has been shown that acetylation of RhoGDI alpha prevents its inhibitory action 
on Rho family members leading to enhanced stress fiber and filopodia formation [4]. RhoA can also be inhibited by the E-cadherin-binding protein p120 catenin. Acetylation of p120 changes its subcellular localisation thereby relieving its inhibitory action on RhoA [4]. Racl activation, leading to membrane ruffle formation, associated macropinocytosis, and cell migration, depends on deacetylation of the chaperon Hsp90 by HDAC6, but the precise sequence of events has not been elucidated [62].

Muscle contraction can also be regulated by acetylation as observed for actomyosin filament activity in cardiac muscle cells. In fact the muscle LIM protein (MLP), which colocalizes with myofilaments at the $Z$-disc of sarcomeres, is a mechanical stretch sensor. Acetylation of MLP by PCAF enhances the calcium sensitivity of myofilaments. HDAC4 seems to be the deacetylase responsible for MLP deacetylation [103].

3.1.2. Microtubules. As already mentioned, $\alpha$-tubulin, which together with $\beta$-tubulin forms the heterodimeric building block of microtubules, was the first cytoplasmic protein described to be acetylated [2,3]. $\alpha$-tubulin is acetylated on lysine 40 which, until recently, was considered to be the only acetylated lysine residue in tubulin isoforms. Interestingly, in a recent systematic proteomic identification approach for acetylated proteins, lysine 40 of $\alpha$-tubulin was not identified. This is most probably due to the fact that an immunoprecipitation step using a pan acetylated lysine antibody has been used in this approach, which most probably has a low affinity for this particular residue. However, several other acetylated lysine residues in different tubulin isoforms ( $\alpha$ as well as $\beta$ subunits) were detected, but their role and significance have still to be elucidated [5]. Even our understanding of the functional role of the acetylation at lysine 40 of $\alpha$-tubulin is not clear cut. The reason for this may come from the fact that the expression of nonacetylatable $\alpha$-tubulin does not result in any obvious phenotype [104-106], nor does hyperacetylation following KO of HDAC6 [107]. In general, acetylated microtubules are considered to represent the subpopulation of more stable microtubules in the cell. There has been however a long debate in the literature as to whether acetylation is the cause or a consequence of microtubule stabilisation. While it has been suggested that acetylation just accumulates with time in microtubules with a long half-life [108], others have proposed that acetylation could directly stabilise microtubules [50,51]. Yet, hyperacetylation in neuronal cells does not lead to microtubule stabilisation [109]. Also, in cells KO for the tubulin deacetylase HDAC6, hyperacetylation of microtubules is not accompanied by detyrosination, which is the other hallmark of stable microtubules [62]. Thus we are proposing an alternative hypothesis for the role of tubulin acetylation. In fact, acetylated microtubules are not very abundant in most of the cells cultured in vitro. There are, however, a few exceptions. At least three cell types have heavily acetylated microtubules in their cytoplasm; these are neurons, platelets, and megacaryocytes, the platelet progenitors. In addition there are cellular substructures formed by microtubules, which are also heavily acetylated like primary cilia, flagella, mitotic spindles and midbodies. What all these structures and cell types have in common is the need of microtubule bundles. Thus acetylation may allow for more efficient bundling of microtubules, which in turn may lead to enhanced stability of these microtubule bundles. In support of this hypothesis are several observations described in the literature. Naranatt et al. have shown that, 30 min after infection of cells by HHV-8, a transient increase of microtubule acetylation is seen which is accompanied by a thickening of microtubule bundles. Both, acetylation as well as the thickening of microtubules, come back to basal levels about 2-3 hours after infection [110]. Similarly, pneumolysin, a virulence factor of streptococcus pneumonia, can induce microtubule acetylation and concomitant microtubule bundling [111]. Also, overexpression of calpain 6, a catalytically inactive calpain isoform, induces hyperacetylation and bundling of microtubules [112]. Another example is the tubulin polymerisation promoting protein TPPP/p25, which induces not only tubulin polymerisation but also acetylation and subsequent bundling and stabilisation of microtubules [68]. Microtubule bundles are also promoted by 180 , a rough ER associated protein, after induction of tubulin acetylation [113]. In addition, early during neuronal commitment an acetylated array of microtubules is formed which is arranged in a bundle of parallel microtubules [114].

Besides its contribution in stabilisation and/or bundling of microtubules, tubulin acetylation plays an important role in cellular transport events as discussed below. It should be mentioned here that there is a coordinated interplay between the actin cytoskeleton and the microtubular network of which one coordinator is the RhoA effector Dia [115, $116]$, which can bind to microtubules and, as mentioned above, also binds to actin filaments. In fact Dia has been shown to influence microtubule orientation, stability and acetylation states. Some of the studies conducted so far describe enhanced microtubule acetylation following RhoA and Dia activation [110, 117-119]. It is not known, however, whether in these cases enhanced acetylation is due to direct Dia mediated HDAC6 inhibition or to activation of a tubulin acetyltransferase. In another study using osteoclasts, Dia activation leads to the opposite effect namely deacetylation of microtubules due to the interaction of Dia with, and concomitant activation of, HDAC6 [66]. The outcome of Dia activation on microtubule acetylation/stabilisation may thus be cell type dependent. Further complexity might be added to the finetuning of these regulatory events by the fact that a Dia-related isoform seems to be acetylated itself [5].

3.1.3. Intermediate Filaments. At least some of the constituents of the third class of cytoskeletal elements, the intermediate filaments, have also been found acetylated. One example is vimentin, which is acetylated on several lysine residues [5], another is cytokeratin 8, which is acetylated on three lysine residues. In contrast to tubulin and actin however, in this case, acetylation seems to destabilize the polymer [120, 121]. 
3.2. Transport. Cellular transport along microtubule tracks is particularly important in cells, which have long extensions like axons and dendrites of neuronal cells. This may be the reason why the important role of microtubule acetylation for cargo transport has first been observed in neurons. The microtubule motor kinesin is implicated in anterograde transport, whereas dynein motors are involved in retrograde transfer of cellular materials (Figure 1(b)). It has been shown that binding of kinesin-1 to and mobility on microtubules is enhanced by tubulin acetylation and thus delivery of Jip1 (a cargo protein of kinesin-1) to neurite tips is accelerated [122]. Another example of more efficient kinesin-1-mediated transport along acetylated microtubules is the vesicular transport of the neurotrophic factor BDNF. In neurons of Huntington disease patients, BDNF is not transported and secreted efficiently due to a polyglutamine expansion in the htt protein, which is unable to stimulate microtubule-based transport. Hyperacetylation of microtubules can rescue this deficiency. In addition the authors show that both kinesin as well as dynein-dependent microtubular transport is enhanced by tubulin acetylation [109]. Regulation of receptor trafficking by enhancing the speed of endosome transport is also augmented by microtubule acetylation $[72,123]$. EGFR vesicle recycling however is not influenced under these conditions [123]. Collectively, these observations indicate that the transport of individual cargo proteins, as well as some but not all vesicular transport processes, are regulated by microtubule acetylation (Figure 1(b)).

Viruses have developed strategies to profit from the host cellular transport machinery for efficient infection. The herpes virus HHV-8 for instance is able to enhance microtubule acetylation by activation of RhoA and its effector Dia2, which speeds the dynein dependent delivery of viral DNA to the nucleus [110]. The adenovirus acts in a similar way [119]. The vaccinia virus instead inhibits RhoA and, in turn, Dia2 leading to diminished tubulin acetylation but increased tubulin dynamics in the cell periphery, which in this case could help viral release [117]. Efficient invasion of bladder cells by uropathogenic E. coli bacteria also requires HDAC6-mediated deacetylation of microtubules [124].

In the context of cellular transport mechanisms it is worth mentioning that several motor proteins have themselves been identified as being acetylated and future studies will have to tell whether transport regulation attributed to microtubule acetylation could have been influenced also by motor protein acetylation [5].

\subsection{Translation, Quality Control, and Cytoplasmic Cleanup.} Acetylation has been widely studied for its role in transcriptional regulation in the nucleus and it is almost astonishing that, to our knowledge, no observation on translational regulation by acetylation has been described so far. It is worth mentioning, however, that in global proteomic studies a huge number of translation initiation factors or ribosomal proteins have been found acetylated $[4,5]$. Thus a possible role of acetylation in translational control mechanisms remains to be discovered. The amount of expressed proteins is not only controlled at the transcriptional and translational levels but also by regulation of their half-life. Acetylation is widely used to influence protein stability in both directions but, since this topic has been reviewed recently [125], it will not be discussed here.

Besides quantity control, the cell is also equipped with quality control and cleanup systems for cellular proteins to avoid the accumulation of misfolded, aggregated proteins in the cytoplasm, which would have a deleterious effect on coordinated normal cellular functions (Figure 1(c)). Following translation many newly synthesised proteins have to be assisted for correct folding or assembly into multisubunit complexes. This is ensured by chaperones. Chaperones are also implicated in the management of misfolded proteins which arise following different environmental stress conditions like heat shock, oxidative stress and aging, or pathological expression of proteins due to mutations or overexpression. In case of an unsuccessful management by chaperones, misfolded proteins are ubiquitinated and degraded by the proteasome. After a prolonged or extensive stress period or under experimental overexpression of proteins, the chaperone/proteasome pathway cannot cope anymore with the massive conformational defects of proteins, which accumulate and aggregate in the cytoplasm. This gives rise to a more global stress response, leading to stress granules and aggresome formation and induction of QC-autophagy. The important role of HDAC6 in all of these different cellular defence mechanisms has been well described (for review see $[76,77])$ and will not be discussed in detail in this paper. We will rather emphasize the critical importance of some acetylated lysine residues within other key actors involved in these processes.

\subsubsection{Chaperones/Proteasome. Chaperones are well known} as proteins assisting nucleosome formation. There are however also several chaperones important for the folding or assembly of cytoplasmic protein complexes and many chaperones have been discovered following heat shock treatment, which leads not only to their transcriptional induction but also to their immediate activation. Hsp90 can be acetylated on several lysine residues and its activation state depends on its acetylation status. Its immediate activation is mediated by HDAC6-dependent deacetylation, which is essential for ATP binding of Hsp90 [54] and for its binding to its cochaperone p23 as well as to various client proteins like AhR (aryl hydrocarbon receptor) [126], BcrAbl, AKT, c-Raf [54], or the glucocorticoid receptor [57, 127]. Besides other acetylated lysine residues deacetylation of lysine 294 in Hsp90 is particularly important for cochaperone and client binding [56] but, as mentioned above, HDAC6 mediated deacetylation of this site is also responsible for Hsp90 mediated Rac1 activation resulting in actin reorganisation and cell migration [62]. The different functional roles of Hsp90 could be dictated by its cellular localisation since Hsp90 is translocated to membrane ruffles to mediate its role in actin remodelling [62]. By deacetylation of Hsp90, HDAC6 may regulate its own survival since HDAC6 has been shown to be itself an Hsp90 client protein [128]. 
Alpha A-crystallin, a chaperone in the soluble fraction of eye lenses, becomes acetylated on lysine 70, a region supposed to be important for its activity, and alphaB-crystallin appears to be acetylated on lysine $92[129,130]$. Crystallins may thus be another example of chaperones whose activity is regulated by acetylation. The chaperone DNAJB8 can be acetylated on two conserved lysine residues situated in its carboxyterminal part. Although these lysine residues are not implicated in substrate binding, deacetylation mediated by HDAC4 activates the chaperone and suppresses cytotoxic protein aggregation [131].

As mentioned above, in case chaperones are unable to assist correct folding of their client proteins, these misfolded proteins are eliminated by proteasomal degradation. One example is again Hsp90. In its inactive ADP-bound state it associates with the cochaperone Hsp70, which prepares the misfolded client protein for degradation by its association with a ubiquitin ligase. Hsp70 is also hyperacetylated following either class I HDAC or HDAC6 inhibition. In contrast to Hsp90, hyperacetylation of Hsp70 promotes its interaction with client proteins leading to their ubiquitination and degradation by the proteasome [132].

3.3.2. Stress Granules/Aggresome/Autophagy. When the load of misfolded proteins is too high the cells suspend their normal function and respond with an immediate block of mRNA translation (except for stress response factors like heat shock proteins/chaperones). Accumulation of the halted transcripts gives rise to the appearance of stress granules. In parallel, the accumulating misfolded proteins become ubiquitinated and transported along microtubules to the centrosome where they form the so-called aggresome. HDAC6 is essential for both stress granule and aggresome formation $[133,134]$. It has been suggested that HDAC6 could act in the transport process as an adaptor by binding to the dynein motor complex on the one hand and binding via its ubiquitin binding domain to ubiquitinated proteins on the other [133]. Parkin, a ubiquitin E3 ligase (often mutated in Parkinson disease), tightly binds to HDAC6 and is also transported by HDAC6 in a microtubule motor dependent manner to the forming aggresome. There may be ongoing parkin-mediated ubiquitination of misfolded proteins during transport along the microtubules $[135,136]$. Given that microtubule motordependent transport is enhanced when microtubules are acetylated one would expect that the deacetylase activity of HDAC6 is inhibited during these transport processes and that deacetylase deficient forms of HDAC6 should be able to rescue stress granule and aggresome formation in HDAC6 $\mathrm{KO}$ cells. Since this is not the case and in addition, HDAC6 and parkin are both active during the transport to the aggresome, it seems that a deacetylation event is essential for aggresome and stress granule formation. Whether tubuline is the relevant substrate or not remains to be determined.

Aggresomes or smaller ubiquitinated misfolded protein aggregates are cleared by basal or QC-autophagy. Double membranous vesicular compartments called autophagosomes are formed in order to isolate the cytoplasm containing the material to be eliminated. These vesicles then fuse with lysosomes, and the lysosomal enzymes ensure the proteolytic digestion of their content. HDAC6 is essential for the delivery of autophagosomal constituents and lysosomes to the pericentriolar localised aggresome by transport along microtubule tracts, as observed for the clearing of aggregated huntington [137]. HDAC6 then plays a second role in the fusion between autophagosomes and lysosomes by recruiting and deacetylating cortactin which in turn recruits actin filaments to tether the two vesicle populations $[138,139]$. QC-autophagy can be distinguished from starvation-induced autophagy since the latter does not depend on HDAC6. Both, however, depend on the same autophagy-related genes (Atg). Recent studies have shown that starvation-induced autophagy is regulated by the acetylation status of Atg5, Atg7, and Atg8, which are proteins required for the formation of the autophagosome. They are acetylated by $\mathrm{p} 300$, which prevents autophagosome formation [140]. Deacetylation is accomplished by Sirt1 and is essential for the induction of autophagy following nutrient deprivation [90]. This observation correlates with the fact that Sirtl is implicated in metabolic processes and upregulated during fasting conditions [141]. Stimulation of starvation-induced autophagy requires also hyperacetylation of tubulin, which could explain why the absence of HDAC6 does not prevent this type of autophagy [142].

3.4. Plasma Membrane and Organelles. Several ion pumps of the plasma membrane, like the $\mathrm{Na}^{+} / \mathrm{K}^{+}$-ATPase and the $\mathrm{Ca}^{2 \pm}$ ATPase can associate with acetylated microtubules or acetylated tubulin dimers but not with unacetylated tubulin. Association with acetylated tubulin inhibits the pumps and may serve at the same time as an anchorage site for the microtubular network to the plasma membrane [143]. Acetylated tubulin at the plasma membrane is also found in another context. The viral protein gp120 of HIV binds to its receptor CD4 in the plasma membrane of T cells and induces tubulin acetylation and accumulation at contact sites. These plasma membrane domains rich in acetylated tubulin could be entry sites for HIV, since active HDAC6 diminishes HIV infection [144].

Mitochondria harbour an enormous amount of acetylated proteins, and there are several publications on the important role of acetylation for the regulation of metabolic and age-related processes, which could not be included in this paper.

Interestingly, recent studies describe acetylation and deacetylation events occurring in the lumen of the ER and Golgi apparatus, respectively. Bace1, the protease responsible for amyloid precursor protein cleavage, and the LDL receptor become acetylated in the ERGIC $[145,146]$. Acetylation is essential for their stabilisation and progression along the secretory pathway. Both proteins are deacetylated in the Golgi apparatus. This implies not only the presence of Hats and HDACs in these cellular compartments but also an ER import system for acetyl-CoA. While the responsible Hat enzymes have been identified and appear to be type II membrane proteins, the HDACs still remain to be discovered and 
the acetyl-CoA transporter is currently under investigation [147].

3.5. Nuclear-Cytoplasmic Shuttle. Besides the regulation of protein stability, activity and interactions, acetylation is widely used for regulating the cellular localization of proteins, especially for nuclear import and export (Figure 1(b)). Most proteins, which shuttle between the nucleus and the cytoplasm, are acetylated by p300/CBP, including HNF-4, CIITA, PCNA, SRY, cAbl, CtBP2, p53, PAP, and $\beta$-catenin, RECQL4 [148-157]. Two out of those can also be acetylated by PCAF $[154,155]$, and there is only one report published so far where Gcn5-mediated acetylation plays a role, concerning CDC6 [158]. Until now no general rule for the localisation of the acetylated subpopulation of proteins has been deciphered. For some proteins, acetylation enhances localisation in the cytoplasm [149, 151, 153, 154, 158, 159], whereas for others acetylation will preferentially favour a nuclear localization $[148,150,152,155,156,160,161]$. The mechanism by which acetylation influences cellular localisation can be either the modification of an interaction with a binding partner leading to retention in a particular compartment, or an altered interaction with nuclear import/export factors. For poly(A) polymerase (PAP) and the DNA helicase RECQL4 it was shown that acetylation disrupts their interaction with the nuclear import factors leading to their accumulation in the cytoplasm $[149,153]$. In contrast, SRY acetylation provokes its nuclear import, which also depends on its interaction with a nuclear import factor, but in this case acetylation induces an increased interaction of the acetylated form with importin beta [148]. Interestingly, in order to stay in the nucleus HNF-4 has to be kept in an acetylated state at its NLS. Deacetylation leads to CRM1-dependent export most probably after a conformational change liberating its nuclear export signal [156]. Similarly, cytoplasmic localisation of acetylated p53 depends on CRM1 binding to its nuclear export signal which is accessible only when p53 oligomerization is prevented by lysine acetylation [151]. Another example of CRM1dependent export regulated by acetylation is NF-kappaB. When present in the nucleus the RelA subunit of NFkappaB can be acetylated on several lysine residues, which differentially influence its nuclear export mediated by the NF-kappaB inhibitor IkappaBalpha [161, 162].

Interestingly, the nuclear import factor importin alpha is itself targeted by reversible acetylation by p300/CBP, which stimulates heterodimer formation with importin beta $[163,164]$. In addition, several other transport factors are among the acetylated proteins identified by Choudhary et al. These include importin beta as well as CAS, the exportin responsible for recycling importin alpha to the cytoplasm, and the more general export receptor CRM1 [5].

\section{Concluding Remarks}

The overwhelming amount of published work on important aspects of cytoplasmic acetylation precludes an exhaustive overview covering the current knowledge (for additional aspects see [165]). We have therefore focused on selected examples illustrating some important points and wish to apologize for other interesting observations, which have not been included.

Having discussed the importance of acetylation in the cytoplasm, it may be worth insisting on the fact that cells should be considered as entities which cannot be strictly divided into two different compartments. The interpretation of some of the results might have been biased by indirect effects due to transcriptional regulation or leakage of nuclear proteins during biochemical purification steps. Also proteins generally considered as typical cytoplasmic residents do play important roles in the nucleus. Actin, for instance, known as a major cytoskeletal and thus cytoplasmic constituent, also plays important roles in the nucleus as a part of transcription or DNA remodelling complexes. Even tubulin was recently found translocating between the nucleus and the cytoplasm [166]. To circumvent problems related to the presence of the nucleus for the characterisation of cytoplasmic acetylation events, we propose platelets as a good model system. Platelets are devoid of a nucleus but are equipped with all the important players to execute known cytoplasmic processes like exocytosis, adhesion, aggregation, shape change, remodelling of the cytoskeleton, and even apoptosis-related events. Furthermore all these processes have to be tightly regulated and induction has to be extremely rapid to ensure hemostasis and prevent thrombosis.

We would like to conclude with the prediction that, although numerous acetylated proteins have been already identified in the cytoplasm, there are likely more to be discovered. This idea is supported by the fact that acetylation of lysine 40 of alpha tubulin has not been detected in the proteomic survey of acetylated proteins by Choudhary et al. [5] and other acetylation sites may have been missed for the same technical reasons (see above). New strategies including bioinformatic prediction approaches $[167,168]$ may lead us to new candidates for reversible acetylation. We therefore believe that the story will not end here and future will tell us more about acetylated proteins and exciting new regulatory mechanisms. Finally this paper highlights the importance of reversible cytoplasmic protein acetylation in a wide range of cellular functions and regulatory mechanisms. The functional significance of this modification has been largely recognized in the past for transcriptional control mechanisms in the nucleus and at present, as summarized here, also for cytoplasmic events. Thus the functional role of reversible protein lysine acetylation now definitely approaches the regulatory power of protein phosphorylation as rightly predicted by Kouzarides [169].

\section{Abbreviations}

ADP: Adenosine diphosphate

AhR: Aryl hydrocarbon Receptor

Arp: Actin-related protein

ATAC: Ada Two-A Containing

ATF2: Activating Transcription

Factor 2 


\begin{tabular}{|c|c|}
\hline ATP: & Adenosine triphosphate \\
\hline BBIP10: & $\begin{array}{l}\text { BBSome Interacting Protein } \\
10\end{array}$ \\
\hline BDNF: & $\begin{array}{l}\text { Brain Derived Neurotrophic } \\
\text { Factor }\end{array}$ \\
\hline Cbl: & Casitas B-lineage lymphoma \\
\hline CBP: & CREB Binding Protein \\
\hline CD: & Cluster of Differentiation \\
\hline CDC6: & Cell Division Cycle 6 \\
\hline CRM1: & $\begin{array}{l}\text { Chromosome Region } \\
\text { Maintenance } 1\end{array}$ \\
\hline EGFR: & $\begin{array}{l}\text { Epidermal Growth Factor } \\
\text { Receptor }\end{array}$ \\
\hline Elp3: & Elongator complex protein 3 \\
\hline ER: & Endoplasmic Reticulum \\
\hline ERGIC: & $\begin{array}{l}\text { Endoplasmic } \\
\text { Reticulum-Golgi } \\
\text { Intermediate Compartment }\end{array}$ \\
\hline Gcn5: & $\begin{array}{l}\text { General control of amino acid } \\
\text { synthesis } 5\end{array}$ \\
\hline Hat: & Histone acetyltransferase \\
\hline HDAC: & Histone deacetylase \\
\hline HHV-8: & Human Herpes Virus 8 \\
\hline HIV: & $\begin{array}{l}\text { Human Immunodeficiency } \\
\text { Virus }\end{array}$ \\
\hline HNF-4: & Hepatocyte Nuclear Factor 4 \\
\hline HSP90: & Heat Shock Protein 90 \\
\hline KAT: & lysine $(\mathrm{K})$ acetyltransferase \\
\hline LDL: & Low-density Lipoprotein \\
\hline MYST: & MOZ, Ybf2/Sas3, Sas2, Tip60 \\
\hline NAD: & $\begin{array}{l}\text { Nicotinamide Adenine } \\
\text { Dinucleotide }\end{array}$ \\
\hline NF-kappaB: & Nuclear Factor-kappaB \\
\hline NGF: & Nerve Growth Factor \\
\hline NLS: & Nuclear Localization Signal \\
\hline PAP: & Poly A Polymerase \\
\hline PCAF: & p300/CBP-associated Factor \\
\hline PCNA: & $\begin{array}{l}\text { Proliferating Cell Nuclear } \\
\text { Antigen }\end{array}$ \\
\hline PDGF: & $\begin{array}{l}\text { Platelet-derived Growth } \\
\text { Factor }\end{array}$ \\
\hline QC-autophagy: & Quality Control-autophagy \\
\hline Racl: & $\begin{array}{l}\text { Ras-related C3 botulinum } \\
\text { toxin substrate } 1\end{array}$ \\
\hline RECQL4: & RecQ protein-like 4 \\
\hline Rho: & Ras homolog gene \\
\hline RNAi: & RNA interference \\
\hline SAGA: & $\begin{array}{l}\text { Spt-Ada-Gcn } 5 \\
\text { Acetyltransferase }\end{array}$ \\
\hline Sirt: & Sirtuin \\
\hline SRY: & Sex-determining Region $\mathrm{Y}$ \\
\hline STAGA: & $\begin{array}{l}\text { SPT3-TAF9-GCN5/PCAF } \\
\text { acetylase }\end{array}$ \\
\hline TFTC: & $\begin{array}{l}\text { TBP-free TAF-containing } \\
\text { Complex }\end{array}$ \\
\hline Tip60: & Tat interacting protein 60 \\
\hline TNF: & Tumor Necrosis Factor \\
\hline
\end{tabular}

TPPP: Tubulin

Polymerization-Promoting

Protein

tRNA: transfer RNA.

\section{Acknowledgments}

The authors gratefully acknowledge Dr. Sophie Rousseaux and Dr. Olivier Destaing for critical reading of the paper. Saadi Khochbin's laboratory was supported by INCa-DHOS, ANR blanche "EpiSperm" and "Empreinte", and ARC research programs.

\section{References}

[1] V. G. Allfrey, R. Faulkner, and A. E. Mirsky, "Acetylation and methylation of histones and their possible role in the regulation of rna synthesis," Proceedings of the National Academy of Sciences of the United States of America, vol. 51, pp. 786-794, 1964.

[2] S. W. L'Hernault and J. L. Rosenbaum, "Chlamydomonas $\alpha$ tubulin is posttranslationally modified by acetylation on the $\varepsilon$-amino group of a lysine," Biochemistry, vol. 24, no. 2, pp. 473-478, 1985.

[3] G. Piperno and M. T. Fuller, "Monoclonal antibodies specific for an acetylated form of $\alpha$-tubulin recognize the antigen in cilia and flagella from a variety of organisms," Journal of Cell Biology, vol. 101, no. 6, pp. 2085-2094, 1985.

[4] S. C. Kim, R. Sprung, Y. Chen et al., "Substrate and functional diversity of lysine acetylation revealed by a proteomics survey," Molecular Cell, vol. 23, no. 4, pp. 607-618, 2006.

[5] C. Choudhary, C. Kumar, F. Gnad et al., "Lysine acetylation targets protein complexes and co-regulates major cellular functions," Science, vol. 325, no. 5942, pp. 834-840, 2009.

[6] C. D. Allis, S. L. Berger, J. Cote et al., "New nomenclature for chromatin-modifying enzymes," Cell, vol. 131, no. 4, pp. 633-636, 2007.

[7] M. R. Parthun, "Hat1: the emerging cellular roles of a type B histone acetyltransferase," Oncogene, vol. 26, no. 37, pp. 5319-5328, 2007.

[8] E. L. Mersfelder and M. R. Parthun, "Involvement of Hat1p (Katlp) catalytic activity and subcellular localization in telomeric silencing," The Journal of Biological Chemistry, vol. 283, no. 43, pp. 29060-29068, 2008.

[9] A. B. Ruiz-García, R. Sendra, M. Galiana, M. Pamblanco, J. E. Pérez-Ortín, and V. Tordera, "Hat1 and Hat2 proteins are components of a yeast nuclear histone acetyltransferase enzyme specific for free histone H4," The Journal of Biological Chemistry, vol. 273, no. 20, pp. 12599-12605, 1998.

[10] A. Imhof and A. P. Wolffe, "Purification and properties of the Xenopus Hat 1 acetyltransferase: association with the 14-3-3 proteins in the oocyte nucleus," Biochemistry, vol. 38, no. 40, pp. 13085-13093, 1999.

[11] I. M. Seiden-Long, K. R. Brown, W. Shih et al., "Transcriptional targets of hepatocyte growth factor signaling and Kiras oncogene activation in colorectal cancer," Oncogene, vol. 25, no. 1, pp. 91-102, 2006.

[12] E. A. Lebel, P. Boukamp, and S. T. Tafrov, "Irradiation with heavy-ion particles changes the cellular distribution of human histone acetyltransferase HAT1," Molecular and Cellular Biochemistry, vol. 339, no. 1-2, pp. 271-284, 2010. 
[13] K. Wong, J. Zhang, S. Awasthi et al., "Nerve growth factor receptor signaling induces histone acetyltransferase domaindependent nuclear translocation of p300/CREB-binding protein-associated factor and hGCN5 acetyltransferases," The Journal of Biological Chemistry, vol. 279, no. 53, pp. 55667-55674, 2004.

[14] N. Blanco-García, E. Asensio-Juan, X. De La Cruz, and M. A. Martínez-Balbás, "Autoacetylation regulates P/CAF nuclear localization," The Journal of Biological Chemistry, vol. 284, no. 3, pp. 1343-1352, 2009.

[15] R. P. S. Kwok, X.-T. Liu, and G. D. Smith, "Distribution of coactivators CBP and p300 during mouse oocyte and embryo development," Molecular Reproduction and Development, vol. 73, no. 7, pp. 885-894, 2006.

[16] M. E. Fermento, N. A. Gandini, C. A. Lang et al., "Intracellular distribution of p300 and its differential recruitment to aggresomes in breast cancer," Experimental and Molecular Pathology, vol. 88, no. 2, pp. 256-264, 2010.

[17] M. R. Hass and B. A. Yankner, "A $\gamma$-secretase-independent mechanism of signal transduction by the amyloid precursor protein," The Journal of Biological Chemistry, vol. 280, no. 44, pp. 36895-36904, 2005.

[18] Q. Ran and O. M. Pereira-Smith, "Identification of an alternatively spliced form of the Tat Interactive Protein (Tip60), Tip60(ß)," Gene, vol. 258, no. 1-2, pp. 141-146, 2000.

[19] A. M. Sheridan, T. Force, H.-J. Yoon et al., "PLIP, a novel splice variant of Tip60, interacts with group iv cytosolic phospholipase A2, induces apoptosis, and potentiates prostaglandin production," Molecular and Cellular Biology, vol. 21, no. 14, pp. 4470-4481, 2001.

[20] H. Liu, X. Deng, Y. J. Shyu, J. L. Jian, E. J. Taparowsky, and C.-D. Hu, "Mutual regulation of c-Jun and ATF2 by transcriptional activation and subcellular localization," The EMBO Journal, vol. 25, no. 5, pp. 1058-1069, 2006.

[21] H. Maruta, K. Greer, and J. L. Rosenbaum, "The acetylation of alpha-tubulin and its relationship to the assembly and disassembly of microtubules," Journal of Cell Biology, vol. 103, no. 2, pp. 571-579, 1986.

[22] C. Creppe, L. Malinouskaya, M.-L. Volvert et al., "Elongator controls the migration and differentiation of cortical neurons through acetylation of $\alpha$-tubulin," Cell, vol. 136, no. 3, pp. 551-564, 2009.

[23] J. A. Solinger, R. Paolinelli, H. Klöß et al., “The Caenorhabditis elegans elongator complex regulates neuronal $\alpha$-tubulin acetylation," PLoS Genetics, vol. 6, no. 1, Article ID e1000820, 2010.

[24] L. D. Johansen, T. Naumanen, A. Knudsen et al., "IKAP localizes to membrane ruffles with filamin A and regulates actin cytoskeleton organization and cell migration," Journal of Cell Science, vol. 121, no. 6, pp. 854-864, 2008.

[25] P. B. Rahl, C. Z. Chen, and R. N. Collins, "Elplp, the yeast homolog of the FD disease syndrome protein, negatively regulates exocytosis independently of transcriptional elongation," Molecular Cell, vol. 17, no. 6, pp. 841-853, 2005.

[26] J. Q. Svejstrup, "Elongator complex: how many roles does it play?" Current Opinion in Cell Biology, vol. 19, no. 3, pp. 331336, 2007.

[27] C. Holmberg, S. Katz, M. Lerdrup et al., "A novel specific role for $\mathrm{I} \kappa \mathrm{B}$ kinase complex-associated protein in cytosolic stress signaling," The Journal of Biological Chemistry, vol. 277, no. 35, pp. 31918-31928, 2002.
[28] B. Huang, M. J. O. Johansson, and A. S. Byström, "An early step in wobble uridine tRNA modification requires the Elongator complex," RNA, vol. 11, no. 4, pp. 424-436, 2005.

[29] A. Esberg, B. Huang, M. J. O. Johansson, and A. S. Byström, "Elevated levels of two tRNA species bypass the requirement for elongator complex in transcription and exocytosis," Molecular Cell, vol. 24, no. 1, pp. 139-148, 2006.

[30] C. Chen, S. Tuck, and A. S. Byström, "Defects in tRNA modification associated with neurological and developmental dysfunctions in Caenorhabditis elegans elongator mutants," PLoS Genetics, vol. 5, no. 7, Article ID e1000561, 2009.

[31] M. Conacci-Sorrell, C. Ngouenet, and R. N. Eisenman, "Mycnick: a cytoplasmic cleavage product of Myc that promotes $\alpha$-tubulin acetylation and cell differentiation," Cell, vol. 142, no. 3, pp. 480-493, 2010.

[32] J. S. Akella, D. Wloga, J. Kim et al., "MEC-17 is an $\alpha$-tubulin acetyltransferase," Nature, vol. 467, no. 7312, pp. 218-222, 2010.

[33] N. Ohkawa, S. Sugisaki, E. Tokunaga et al., "N-acetyltransferase ARD1-NAT1 regulates neuronal dendritic development," Genes to Cells, vol. 13, no. 11, pp. 1171-1183, 2008.

[34] Q. Shen, X. Zheng, M. A. McNutt et al., "NAT10, a nucleolar protein, localizes to the midbody and regulates cytokinesis and acetylation of microtubules," Experimental Cell Research, vol. 315, no. 10, pp. 1653-1667, 2009.

[35] J. Y. Kim, S. Shen, K. Dietz et al., "HDAC1 nuclear export induced by pathological conditions is essential for the onset of axonal damage," Nature Neuroscience, vol. 13, no. 2, pp. 180-189, 2010.

[36] W.-M. Yang, S.-C. Tsai, Y.-D. Wen, G. Fejé, and E. Seto, "Functional domains of histone deacetylase-3," The Journal of Biological Chemistry, vol. 277, no. 11, pp. 9447-9454, 2002.

[37] P. Viatour, S. Legrand-Poels, C. Van Lint et al., "Cytoplasmic $\mathrm{I} \kappa \mathrm{B} \alpha$ increases NF- $\kappa \mathrm{B}$-independent transcription through binding to histone deacetylase (HDAC) 1 and HDAC3," The Journal of Biological Chemistry, vol. 278, no. 47, pp. 4654146548, 2003.

[38] Z. Gao, Q. He, B. Peng, P. J. Chiao, and J. Ye, "Regulation of nuclear translocation of HDAC3 by $\mathrm{I} \kappa \mathrm{B} \alpha$ is required for tumor necrosis factor inhibition of peroxisome proliferatoractivated receptor $\gamma$ function," The Journal of Biological Chemistry, vol. 281, no. 7, pp. 4540-4547, 2006.

[39] M. S. Longworth and L. A. Laimins, "Histone deacetylase 3 localizes to the plasma membrane and is a substrate of Src," Oncogene, vol. 25, no. 32, pp. 4495-4500, 2006.

[40] D. Waltregny, W. Glénisson, S. L. Tran et al., "Histone deacetylase HDAC8 associates with smooth muscle $\alpha$-actin and is essential for smooth muscle cell contractility," The FASEB Journal, vol. 19, no. 8, pp. 966-968, 2005.

[41] D. Waltregny, L. De Leval, W. Glénisson et al., "Expression of histone deacetylase 8 , a class I histone deacetylase, is restricted to cells showing smooth muscle differentiation in normal human tissues," American Journal of Pathology, vol. 165, no. 2, pp. 553-564, 2004.

[42] M. Martin, R. Kettmann, and F. Dequiedt, "Class IIa histone deacetylases: conducting development and differentiation," The International Journal of Developmental Biology, vol. 53, no. 2-3, pp. 291-301, 2009.

[43] E. A. Miska, C. Karlsson, E. Langley, S. J. Nielsen, J. Pines, and T. Kouzarides, "HDAC4 deacetylase associates with and represses the MEF2 transcription factor," The EMBO Journal, vol. 18 , no. 18 , pp. 5099-5107, 1999. 
[44] H.-Y. Kao, A. Verdel, C.-C. Tsai, C. Simon, H. Juguilon, and S. Khochbin, "Mechanism for nucleocytoplasmic shuttling of histone deacetylase 7," The Journal of Biological Chemistry, vol. 276, no. 50, pp. 47496-47507, 2001.

[45] R. E. Bakin and M. O. Jung, "Cytoplasmic sequestration of HDAC7 from mitochondrial and nuclear compartments upon initiation of apoptosis," The Journal of Biological Chemistry, vol. 279, no. 49, pp. 51218-51225, 2004.

[46] T. G. Nishino, M. Miyazaki, H. Hoshino, Y. Miwa, S. Horinouchi, and M. Yoshida, "14-3-3 regulates the nuclear import of class IIa histone deacetylases," Biochemical and Biophysical Research Communications, vol. 377, no. 3, pp. 852-856, 2008.

[47] B. C. Harrison, K. Huynh, G. L. Lundgaard, S. M. Helmke, M. B. Perryman, and T. A. McKinsey, "Protein kinase C-related kinase targets nuclear localization signals in a subset of class IIa histone deacetylases," FEBS Letters, vol. 584, no. 6, pp. 1103-1110, 2010.

[48] T. Ago, T. Liu, P. Zhai et al., "A redox-dependent pathway for regulating class II HDACs and cardiac hypertrophy," Cell, vol. 133, no. 6, pp. 978-993, 2008.

[49] C. Gao, X. Li, M. Lam, Y. Liu, S. Chakraborty, and H.-Y. Kao, "CRM1 mediates nuclear export of HDAC7 independently of HDAC7 phosphorylation and association with 14-3-3s," FEBS Letters, vol. 580, no. 21, pp. 5096-5104, 2006.

[50] C. Hubbert, A. Guardiola, R. Shao et al., "HDAC6 is a microtubule-associated deacetylase," Nature, vol. 417, no. 6887, pp. 455-458, 2002.

[51] A. Matsuyama, T. Shimazu, Y. Sumida et al., "In vivo destabilization of dynamic microtubules by HDAC6-mediated deacetylation," EMBO Journal, vol. 21, no. 24, pp. 6820-6831, 2002.

[52] Y. Zhang, N. Li, C. Caron et al., "HDAC-6 interacts with and deacetylates tubulin and microtubules in vivo," $E M B O$ Journal, vol. 22, no. 5, pp. 1168-1179, 2003.

[53] X. Zhang, Z. Yuan, Y. Zhang et al., "HDAC6 modulates cell motility by altering the acetylation level of cortactin," Molecular Cell, vol. 27, no. 2, pp. 197-213, 2007.

[54] P. Bali, M. Pranpat, J. Bradner et al., "Inhibition of histone deacetylase 6 acetylates and disrupts the chaperone function of heat shock protein 90: a novel basis for antileukemia activity of histone deacetylase inhibitors," The Journal of Biological Chemistry, vol. 280, no. 29, pp. 26729-26734, 2005.

[55] S. Aoyagi and T. K. Archer, "Modulating molecular chaperone Hsp90 functions through reversible acetylation," Trends in Cell Biology, vol. 15, no. 11, pp. 565-567, 2005.

[56] B. T. Scroggins, K. Robzyk, D. Wang et al., "An acetylation site in the middle domain of Hsp90 regulates chaperone function," Molecular Cell, vol. 25, no. 1, pp. 151-159, 2007.

[57] J. J. Kovacs, P. J. M. Murphy, S. Gaillard et al., "HDAC6 regulates Hsp90 acetylation and chaperone-dependent activation of glucocorticoid receptor," Molecular Cell, vol. 18, no. 5, pp. 601-607, 2005.

[58] Y. Li, X. Zhang, R. D. Polakiewicz, T.-P. Yao, and M. J. Comb, "HDAC6 is required for epidermal growth factor-induced $\beta$-catenin nuclear localization," The Journal of Biological Chemistry, vol. 283, no. 19, pp. 12686-12690, 2008.

[59] R. B. Parmigiani, W. S. Xu, G. Venta-Perez et al., "HDAC6 is a specific deacetylase of peroxiredoxins and is involved in redox regulation," Proceedings of the National Academy of Sciences of the United States of America, vol. 105, no. 28, pp. 9633-9638, 2008.
[60] A. Verdel, S. Curtet, M.-P. Brocard et al., "Active maintenance of mHDA2/mHDAC6 histone-deacetylase in the cytoplasm," Current Biology, vol. 10, no. 12, pp. 747-749, 2000.

[61] N. R. Bertos, B. Gilquin, G. K. T. Chan, T. J. Yen, S. Khochbin, and X.-J. Yang, "Role of the tetradecapeptide repeat domain of human histone deacetylase 6 in cytoplasmic retention," The Journal of Biological Chemistry, vol. 279, no. 46, pp. 48246-48254, 2004.

[62] Y.-S. Gao, C. C. Hubbert, J. Lu, Y.-S. Lee, J.-Y. Lee, and T.-P. Yao, "Histone deacetylase 6 regulates growth factor-induced actin remodeling and endocytosis," Molecular and Cellular Biology, vol. 27, no. 24, pp. 8637-8647, 2007.

[63] E. Purev, L. Neff, W. C. Horne, and R. Baron, "c-Cbl and Cbl$\mathrm{b}$ act redundantly to protect osteoclasts from apoptosis and to displace HDAC6 from $\beta$-tubulin, stabilizing microtubules and podosomes," Molecular Biology of the Cell, vol. 20, no. 18, pp. 4021-4030, 2009.

[64] J. Zhou, C. C. Vos, A. Gjyrezi et al., "The protein farnesyltransferase regulates HDAC6 activity in a microtubuledependent manner," The Journal of Biological Chemistry, vol. 284, no. 15, pp. 9648-9655, 2009.

[65] A. V. Loktev, Q. Zhang, J. S. Beck et al., "A BBSome subunit links ciliogenesis, microtubule stability, and acetylation," Developmental Cell, vol. 15, no. 6, pp. 854-865, 2008.

[66] O. Destaing, F. Saltel, B. Gilquin et al., "A novel Rho-mDia2HDAC6 pathway controls podosome patterning through microtubule acetylation in osteoclasts," Journal of Cell Science, vol. 118, no. 13, pp. 2901-2911, 2005.

[67] M. Perez, I. Santa-Maria, E. G. De Barreda et al., "Tauan inhibitor of deacetylase HDAC6 function," Journal of Neurochemistry, vol. 109, no. 6, pp. 1756-1766, 2009.

[68] N. Tokési, A. Lehotzky, I. Horváth et al., “TPPP/p25 promotes tubulin acetylation by inhibiting histone deacetylase 6," The Journal of Biological Chemistry, vol. 285, no. 23, pp. 17896-17906, 2010.

[69] H. Ding, P. J. Dolan, and G. V. W. Johnson, "Histone deacetylase 6 interacts with the microtubule-associated protein tau," Journal of Neurochemistry, vol. 106, no. 5, pp. 2119-2130, 2008.

[70] Y. Wu, S. W. Song, J. Sun, J. M. Bruner, G. N. Fuller, and W. Zhang, "IIp45 inhibits cell migration through inhibition of HDAC6," The Journal of Biological Chemistry, vol. 285, no. 6, pp. 3554-3560, 2010.

[71] S. A. Wickström, K. C. Masoumi, S. Khochbin, R. Fässler, and R. Massoumi, "CYLD negatively regulates cell-cycle progression by inactivating HDAC6 and increasing the levels of acetylated tubulin," The EMBO Journal, vol. 29, no. 1, pp. 131-144, 2010.

[72] Y. L. Deribe, P. Wild, A. Chandrashaker et al., "Regulation of epidermal growth factor receptor trafficking by lysine deacetylase HDAC6," Science Signaling, vol. 2, no. 102, p. ra84, 2009.

[73] E. N. Pugacheva, S. A. Jablonski, T. R. Hartman, E. P. Henske, and E. A. Golemis, "HEF1-dependent aurora a activation induces disassembly of the primary cilium," Cell, vol. 129, no. 7, pp. 1351-1363, 2007.

[74] M. H. Brush, A. Guardiola, J. H. Connor, T.-P. Yao, and S. Shenolikar, "Deactylase inhibitors disrupt cellular complexes containing protein phosphatases and deacetylases," The Journal of Biological Chemistry, vol. 279, no. 9, pp. 76857691, 2004.

[75] Y. Han, H. M. Jeong, Y.-H. Jin et al., "Acetylation of histone deacetylase 6 by p300 attenuates its deacetylase activity," 
Biochemical and Biophysical Research Communications, vol. 383, no. 1, pp. 88-92, 2009.

[76] P. Matthias, M. Yoshida, and S. Khochbin, "HDAC6 a new cellular stress surveillance factor," Cell Cycle, vol. 7, no. 1, pp. 7-10, 2008.

[77] C. Boyault, K. Sadoul, M. Pabion, and S. Khochbin, "HDAC6, at the crossroads between cytoskeleton and cell signaling by acetylation and ubiquitination," Oncogene, vol. 26, no. 37, pp. 5468-5476, 2007.

[78] J. J. Tong, J. Liu, N. R. Bertos, and X.-J. Yang, "Identification of HDAC10, a novel class II human histone deacetylase containing a leucine-rich domain," Nucleic Acids Research, vol. 30, no. 5, pp. 1114-1123, 2002.

[79] A. R. Guardiola and T.-P. Yao, "Molecular cloning and characterization of a novel histone deacetylase HDAC10," The Journal of Biological Chemistry, vol. 277, no. 5, pp. 33503356, 2002.

[80] D. D. Fischer, R. Cai, U. Bhatia et al., "Isolation and characterization of a novel class II histone deacetylase, HDAC10," The Journal of Biological Chemistry, vol. 277, no. 8, pp. 6656-6666, 2002.

[81] H.-Y. Kao, C.-H. Lee, A. Komarov, C. C. Han, and R. M. Evans, "Isolation and characterization of mammalian HDAC10, a novel histone deacetylase," The Journal of Biological Chemistry, vol. 277, no. 1, pp. 187-193, 2002.

[82] K. S. Keedy, N. M. Archin, A. T. Gates, A. Espeseth, D. J. Hazuda, and D. M. Margolis, "A limited group of class I histone deacetylases acts to repress human immunodeficiency virus type 1 expression," Journal of Virology, vol. 83, no. 10, pp. 4749-4756, 2009.

[83] L. Gao, M. A. Cueto, F. Asselbergs, and P. Atadja, "Cloning and functional characterization of HDAC11, a novel member of the human histone deacetylase family," The Journal of Biological Chemistry, vol. 277, no. 28, pp. 25748-25755, 2002.

[84] A. Vaquero, "The conserved role of sirtuins in chromatin regulation," The International Journal of Developmental Biology, vol. 53, no. 2-3, pp. 303-322, 2009.

[85] T. L. A. Kawahara, E. Michishita, A. S. Adler et al., "SIRT6 links histone $\mathrm{H} 3$ lysine 9 deacetylation to NF- $\kappa \mathrm{B}$-dependent gene expression and organismal life span," Cell, vol. 136, no. 1, pp. 62-74, 2009.

[86] E. Michishita, J. Y. Park, J. M. Burneskis, J. C. Barrett, and I. Horikawa, "Evolutionarily conserved and nonconserved cellular localizations and functions of human SIRT proteins," Molecular Biology of the Cell, vol. 16, no. 10, pp. 4623-4635, 2005.

[87] M. Tanno, J. Sakamoto, T. Miura, K. Shimamoto, and Y. Horio, "Nucleocytoplasmic shuttling of the NAD+dependent histone deacetylase SIRT1," The Journal of Biological Chemistry, vol. 282, no. 9, pp. 6823-6832, 2007.

[88] T. Sugino, M. Maruyama, M. Tanno, A. Kuno, K. Houkin, and Y. Horio, "Protein deacetylase SIRT1 in the cytoplasm promotes nerve growth factor-induced neurite outgrowth in PC12 cells," FEBS Letters, vol. 584, no. 13, pp. 2821-2826, 2010.

[89] S. Hisahara, S. Chiba, H. Matsumoto et al., "Histone deacetylase SIRT1 modulates neuronal differentiation by its nuclear translocation," Proceedings of the National Academy of Sciences of the United States of America, vol. 105, no. 40, pp. 15599-15604, 2008.

[90] H. L. In, L. Cao, R. Mostoslavsky et al., "A role for the NADdependent deacetylase Sirt1 in the regulation of autophagy," Proceedings of the National Academy of Sciences of the United States of America, vol. 105, no. 9, pp. 3374-3379, 2008.
[91] Y. Zhang, M. Zhang, H. Dong et al., "Deacetylation of cortactin by SIRT1 promotes cell migration," Oncogene, vol. 28, no. 3, pp. 445-460, 2009.

[92] B. J. North and E. Verdin, "Interphase nucleo-cytoplasmic shuttling and localization of SIRT2 during mitosis," PLoS ONE, vol. 2, no. 8, article e784, 2007.

[93] B. J. North, B. L. Marshall, M. T. Borra, J. M. Denu, and E. Verdin, "The human Sir2 ortholog, SIRT2, is an NAD+dependent tubulin deacetylase," Molecular Cell, vol. 11, no. 2, pp. 437-444, 2003.

[94] T. Inoue, M. Hiratsuka, M. Osaki et al., "SIRT2, a tubulin deacetylase, acts to block the entry to chromosome condensation in response to mitotic stress," Oncogene, vol. 26, no. 7, pp. 945-957, 2007.

[95] B. L. Tang and C. E. L. Chua, "SIRT2, tubulin deacetylation, and oligodendroglia differentiation," Cell Motility and the Cytoskeleton, vol. 65, no. 3, pp. 179-182, 2008.

[96] A. L. Garske, B. C. Smith, and J. M. Denu, "Linking SIRT2 to Parkinson's disease," ACS Chemical Biology, vol. 2, no. 8, pp. 529-532, 2007.

[97] T. F. Outeiro, E. Kontopoulos, S. M. Altmann et al., "Sirtuin 2 inhibitors rescue $\alpha$-synuclein-mediated toxicity in models of Parkinson's disease," Science, vol. 317, no. 5837, pp. 516-519, 2007.

[98] N. R. Sundaresan, S. A. Samant, V. B. Pillai, S. B. Rajamohan, and M. P. Gupta, "SIRT3 is a stress-responsive deacetylase in cardiomyocytes that protects cells from stress-mediated cell death by deacetylation of Ku70," Molecular and Cellular Biology, vol. 28, no. 20, pp. 6384-6401, 2008.

[99] M. D. Shahbazian and M. Grunstein, "Functions of SiteSpecific histone acetylation and deacetylation," Annual Review of Biochemistry, vol. 76, pp. 75-100, 2007.

[100] H. Y. Cohen, S. Lavu, K. J. Bitterman et al., "Acetylation of the $\mathrm{C}$ terminus of Ku70 by CBP and PCAF controls Baxmediated apoptosis," Molecular Cell, vol. 13, no. 5, pp. 627638, 2004.

[101] L.-J. Juan, W.-J. Shia, M.-H. Chen et al., "Histone deacetylases specifically down-regulate p53-dependent gene activation," The Journal of Biological Chemistry, vol. 275, no. 27, pp. 20436-20443, 2000.

[102] H. Vaziri, S. K. Dessain, E. N. Eaton et al., "hSIR2SIRT1 functions as an NAD-dependent p53 deacetylase," Cell, vol. 107, no. 2, pp. 149-159, 2001.

[103] M. P. Gupta, S. A. Samant, S. H. Smith, and S. G. Shroff, "HDAC4 and PCAF bind to cardiac sarcomeres and play a role in regulating myofilament contractile activity," The Journal of Biological Chemistry, vol. 283, no. 15, pp. 1013510146, 2008.

[104] T. Fukushige, Z. K. Siddiqui, M. Chou et al., "MEC-12, an $\alpha$ tubulin required for touch sensitivity in C. elegans," Journal of Cell Science, vol. 112, no. 3, pp. 395-403, 1999.

[105] J. Gaertig, M. A. Cruz, J. Bowen, L. Gu, D. G. Pennock, and M. A. Gorovsky, "Acetylation of lysine 40 in $\alpha$-tubulin is not essential in Tetrahymena thermophila," Journal of Cell Biology, vol. 129, no. 5, pp. 1301-1310, 1995.

[106] K. G. Kozminski, D. R. Diener, and J. L. Rosenbaum, "High level expression of nonacetylatable $\alpha$-tubulin in Chlamydomonas reinhardtii," Cell Motility and the Cytoskeleton, vol. 25, no. 2, pp. 158-170, 1993.

[107] Y. Zhang, S. Kwon, T. Yamaguchi et al., "Mice lacking histone deacetylase 6 have hyperacetylated tubulin but are viable and develop normally," Molecular and Cellular Biology, vol. 28, no. 5, pp. 1688-1701, 2008. 
[108] S. J. Haggarty, K. M. Koeller, J. C. Wong, C. M. Grozinger, and S. L. Schreiber, "Domain-selective small-molecule inhibitor of histone deacetylase 6 (HDAC6)-mediated tubulin deacetylation," Proceedings of the National Academy of Sciences of the United States of America, vol. 100, no. 8, pp. 4389-4394, 2003.

[109] J. P. Dompierre, J. D. Godin, B. C. Charrin et al., "Histone deacetylase 6 inhibition compensates for the transport deficit in Huntington's disease by increasing tubulin acetylation," Journal of Neuroscience, vol. 27, no. 13, pp. 3571-3583, 2007.

[110] P. P. Naranatt, H. H. Krishnan, M. S. Smith, and B. Chandran, "Kaposi's sarcoma-associated herpesvirus modulates microtubule dynamics via RhoA-GTP-Diaphanous 2 signaling and utilizes the dynein motors to deliver its DNA to the nucleus," Journal of Virology, vol. 79, no. 2, pp. 1191-1206, 2005.

[111] A. I. Iliev, J. R. Djannatian, F. Opazo et al., "Rapid microtubule bundling and stabilization by the Streptococcus pneumoniae neurotoxin pneumolysin in a cholesterol-dependent, non-lytic and Src-kinase dependent manner inhibits intracellular trafficking," Molecular Microbiology, vol. 71, no. 2, pp. 461-477, 2009.

[112] K. Tonami, Y. Kurihara, H. Aburatani, Y. Uchijima, T. Asano, and H. Kurihara, "Calpain 6 is involved in microtubule stabilization and cytoskeletal organization," Molecular and Cellular Biology, vol. 27, no. 7, pp. 2548-2561, 2007.

[113] K. Ogawa-Goto, K. Tanaka, T. Ueno et al., "p180 is involved in the interaction between the endoplasmic reticulum and microtubules through a novel microtubule-binding and bundling domain," Molecular Biology of the Cell, vol. 18, no. 10, pp. 3741-3751, 2007.

[114] M. M. Falconer, U. Vielkind, and D. L. Brown, "Establishment of a stable, acetylated microtubule bundle during neuronal commitment," Cell Motility and the Cytoskeleton, vol. 12, no. 3, pp. 169-180, 1989.

[115] T. Ishizaki, Y. Morishima, M. Okamoto, T. Furuyashiki, T. Kato, and S. Narumiya, "Coordination of microtubules and the actin cytoskeleton by the Rho effector mDial," Nature Cell Biology, vol. 3, no. 1, pp. 8-14, 2001.

[116] A. F. Palazzo, T. A. Cook, A. S. Alberts, and G. G. Gundersen, "mDia mediates Rho-regulated formation and orientation of stable microtubules," Nature Cell Biology, vol. 3, no. 8, pp. 723-729, 2001.

[117] Y. Arakawa, J. V. Cordeiro, and M. Way, "F11L-mediated inhibition of RhoA-mDia signaling stimulates microtubule dynamics during vaccinia virus infection," Cell Host and Microbe, vol. 1, no. 3, pp. 213-226, 2007.

[118] A. F. Palazzo, C. H. Eng, D. D. Schlaepfer, E. E. Marcantonio, and G. G. Gundersen, "Localized stabilization of microtubules by integrin- and FAK-facilitated Rho signaling," Science, vol. 303, no. 5659, pp. 836-839, 2004.

[119] J. C. Warren, A. Rutkowski, and L. Cassimeris, "Infection with replication-deficient adenovirus induces changes in the dynamic instability of host cell microtubules," Molecular Biology of the Cell, vol. 17, no. 8, pp. 3557-3568, 2006.

[120] P. J. M. Drake, G. J. Griffiths, L. Shaw, R. P. Benson, and B. M. Corfe, "Application of high-content analysis to the study of post-translational modifications of the cytoskeleton," Journal of Proteome Research, vol. 8, no. 1, pp. 28-34, 2009.

[121] S. H. Leech, C. A. Evans, L. Shaw et al., "Proteomic analyses of intermediate filaments reveals cytokeratin8 is highly acetylated-implications for colorectal epithelial homeostasis," Proteomics, vol. 8, no. 2, pp. 279-288, 2008.

[122] N. A. Reed, D. Cai, T. L. Blasius et al., "Microtubule acetylation promotes Kinesin-1 binding and transport," Current Biology, vol. 16, no. 21, pp. 2166-2172, 2006.
[123] Y.-S. Gao, C. C. Hubbert, and T.-P. Yao, "The microtubuleassociated histone deacetylase 6 (HDAC6) regulates epidermal growth factor receptor (EGFR) endocytic trafficking and degradation," The Journal of Biological Chemistry, vol. 285, no. 15, pp. 11219-11226, 2010.

[124] B. K. Dhakal and M. A. Mulvey, "Uropathogenic escherichia coli invades host cells via an HDAC6-modulated microtubule-dependent pathway," The Journal of Biological Chemistry, vol. 284, no. 1, pp. 446-454, 2009.

[125] K. Sadoul, C. Boyault, M. Pabion, and S. Khochbin, "Regulation of protein turnover by acetyltransferases and deacetylases," Biochimie, vol. 90, no. 2, pp. 306-312, 2008.

[126] V. D. Kekatpure, A. J. Dannenberg, and K. Subbaramaiah, "HDAC6 modulates Hsp90 chaperone activity and regulates activation of aryl hydrocarbon receptor signaling," The Journal of Biological Chemistry, vol. 284, no. 12, pp. 74367445, 2009.

[127] P. J. M. Murphy, Y. Morishima, J. J. Kovacs, T.-P. Yao, and W. B. Pratt, "Regulation of the dynamics of hsp90 action on the glucocorticoid receptor by acetylation/deacetylation of the chaperone," The Journal of Biological Chemistry, vol. 280, no. 40, pp. 33792-33799, 2005.

[128] R. Rao, W. Fiskus, Y. Yang et al., "HDAC6 inhibition enhances 17-AAG mediated abrogation of hsp90 chaperone function in human leukemia cells," Blood, vol. 112, no. 5, pp. 18861893, 2008.

[129] P. P. Lin, R. C. Barry, D. L. Smith, and J. B. Smith, "In vivo acetylation identified at lysine 70 of human lens $\alpha \mathrm{A}$ crystallin," Protein Science, vol. 7, no. 6, pp. 1451-1457, 1998.

[130] V. N. Lapko, D. L. Smith, and J. B. Smith, "In vivo carbamylation and acetylation of water-soluble human lens $\alpha \mathrm{B}$ crystallin lysine 92," Protein Science, vol. 10, no. 6, pp. 11301136, 2001.

[131] J. Hageman, M. A. Rujano, M. A.W.H. van Waarde et al., "A DNAJB chaperone subfamily with HDAC-dependent activities suppresses toxic protein aggregation," Molecular Cell, vol. 37, no. 3, pp. 355-369, 2010.

[132] Y. Wang, S.-Y. Wang, X.-H. Zhang et al., "FK228 inhibits Hsp90 chaperone function in K562 cells via hyperacetylation of Hsp70," Biochemical and Biophysical Research Communications, vol. 356, no. 4, pp. 998-1003, 2007.

[133] Y. Kawaguchi, J. J. Kovacs, A. McLaurin, J. M. Vance, A. Ito, and T.-P. Yao, "The deacetylase HDAC6 regulates aggresome formation and cell viability in response to misfolded protein stress," Cell, vol. 115, no. 6, pp. 727-738, 2003.

[134] S. Kwon, Y. Zhang, and P. Matthias, "The deacetylase HDAC6 is a novel critical component of stress granules involved in the stress response," Genes and Development, vol. 21, no. 24, pp. 3381-3394, 2007.

[135] Q. Jiang, Y. Ren, and J. Feng, "Direct binding with histone deacetylase 6 mediates the reversible recruitment of parkin to the centrosome," Journal of Neuroscience, vol. 28, no. 48, pp. 12993-13002, 2008.

[136] J. A. Olzmann, A. Li, M. V. Chudaev et al., "Parkin-mediated K63-linked polyubiquitination targets misfolded DJ-1 to aggresomes via binding to HDAC6," Journal of Cell Biology, vol. 178, no. 6, pp. 1025-1038, 2007.

[137] A. Iwata, B. E. Riley, J. A. Johnston, and R. R. Kopito, "HDAC6 and microtubules are required for autophagic degradation of aggregated Huntingtin," The Journal of Biological Chemistry, vol. 280, no. 48, pp. 40282-40292, 2005.

[138] J.-Y. Lee and T.-P. Yao, "Quality control autophagy: a joint effort of ubiquitin, protein deacetylase and actin cytoskeleton," Autophagy, vol. 6, no. 4, pp. 555-557, 2010. 
[139] J.-Y. Lee, H. Koga, Y. Kawaguchi et al., "HDAC6 controls autophagosome maturation essential for ubiquitin-selective quality-control autophagy," The EMBO Journal, vol. 29, no. 5, pp. 969-980, 2010.

[140] I. H. Lee and T. Finkel, "Regulation of autophagy by the p300 acetyltransferase," The Journal of Biological Chemistry, vol. 284, no. 10, pp. 6322-6328, 2009.

[141] G. Boily, E. L. Seifert, L. Bevilacqua et al., "SirT1 regulates energy metabolism and response to caloric restriction in mice," PLoS ONE, vol. 3, no. 3, Article ID e1759, 2008.

[142] C. Geeraert, A. Ratier, S. G. Pfisterer et al., "Starvationinduced hyperacetylation of tubulin is required for the stimulation of autophagy by nutrient deprivation," The Journal of Biological Chemistry, vol. 285, no. 31, pp. 2418424194, 2010.

[143] G. G. Zampar, M. E. Chesta, A. Carbajal et al., "Acetylated tubulin associates with the fifth cytoplasmic domain of $\mathrm{Na}^{+} / \mathrm{K}^{+}$-ATPase: possible anchorage site of microtubules to the plasma membrane," Biochemical Journal, vol. 422, no. 1, pp. 129-137, 2009.

[144] A. Valenzuela-Fernandez, S. Álvarez, M. Gordon-Alonso et al., "Histone deacetylase 6 regulates human immunodeficiency virus type 1 infection," Molecular Biology of the Cell, vol. 16, no. 11, pp. 5445-5454, 2005.

[145] C. Costantini, M. H. Ko, M. C. Jonas, and L. Puglielli, "A reversible form of lysine acetylation in the ER and Golgi lumen controls the molecular stabilization of BACE1," Biochemical Journal, vol. 407, no. 3, pp. 383-395, 2007.

[146] M. C. Jonas, C. Costantini, and L. Puglielli, "PCSK9 is required for the disposal of non-acetylated intermediates of the nascent membrane protein BACE1," EMBO Reports, vol. 9, no. 9, pp. 916-922, 2008.

[147] H. K. Mi and L. Puglielli, "Two Endoplasmic Reticulum (ER)/ER golgi intermediate compartment-based lysine acetyltransferases post-translationally regulate BACE1 levels," The Journal of Biological Chemistry, vol. 284, no. 4, pp. 2482-2492, 2009.

[148] L. Thevenet, C. Méjean, B. Moniot et al., "Regulation of human SRY subcellular distribution by its acetylation/deacetylation," The EMBO Journal, vol. 23, no. 16, pp. 3336-3345, 2004.

[149] T. Shimazu, S. Horinouchi, and M. Yoshida, "Multiple histone deacetylases and the CREB-binding protein regulate pre-mRNA $3^{\prime}$-end processing," The Journal of Biological Chemistry, vol. 282, no. 7, pp. 4470-4478, 2007.

[150] S. N. Naryzhny and H. Lee, "The post-translational modifications of proliferating cell nuclear antigen: acetylation, not phosphorylation, plays an important role in the regulation of its function," The Journal of Biological Chemistry, vol. 279, no. 19, pp. 20194-20199, 2004.

[151] Y. Kawaguchi, A. Ito, E. Appella, and T.-P. Yao, "Charge modification at multiple c-terminal lysine residues regulates p53 oligomerization and its nucleus-cytoplasm trafficking," The Journal of Biological Chemistry, vol. 281, no. 3, pp. 13941400, 2006.

[152] L.-J. Zhao, T. Subramanian, Y. Zhou, and G. Chinnadurai, "Acetylation by p300 regulates nuclear localization and function of the transcriptional corepressor CtBP2," The Journal of Biological Chemistry, vol. 281, no. 7, pp. 41834189, 2006.

[153] T. Dietschy, I. Shevelev, J. Pena-Diaz et al., "P300-mediated acetylation of the Rothmund-Thomson-syndrome gene product RECQL4 regulates its subcellular localization," Journal of Cell Science, vol. 122, no. 8, pp. 1258-1267, 2009.
[154] M. G. di Bari, L. Ciuffini, M. Mingardi, R. Testi, S. Soddu, and D. Barilà, "c-Abl acetylation by histone acetyltransferases regulates its nuclear-cytoplasmic localization," EMBO Reports, vol. 7, no. 7, pp. 727-733, 2006.

[155] C. Spilianakis, J. Papamatheakis, and A. Kretsovali, "Acetylation by PCAF enhances CIITA nuclear accumulation and transactivation of major histocompatibility complex class II genes," Molecular and Cellular Biology, vol. 20, no. 22, pp. 8489-8498, 2000.

[156] E. Soutoglou, N. Katrakili, and I. Talianidis, "Acetylation regulates transcription factor activity at multiple levels," Molecular Cell, vol. 5, no. 4, pp. 745-751, 2000.

[157] R. Firestein, G. Blander, S. Michan et al., "The SIRT1 deacetylase suppresses intestinal tumorigenesis and colon cancer growth," PLoS ONE, vol. 3, no. 4, Article ID e2020, 2008.

[158] R. Paolinelli, R. Mendoza-Maldonado, A. Cereseto, and M. Giacca, "Acetylation by GCN5 regulates CDC6 phosphorylation in the S phase of the cell cycle," Nature Structural and Molecular Biology, vol. 16, no. 4, pp. 412-420, 2009.

[159] M. P. Valacco, C. Varone, C. Malicet, E. Cánepa, J. L. Iovanna, and S. Moreno, "Cell growth-dependent subcellular localization of p8," Journal of Cellular Biochemistry, vol. 97, no. 5, pp. 1066-1079, 2006.

[160] F. Lan, J. M. Cacicedo, N. Ruderman, and Y. Ido, "SIRT1 modulation of the acetylation status, cytosolic localization, and activity of LKB1: possible role in AMP-activated protein kinase activation," The Journal of Biological Chemistry, vol. 283, no. 41, pp. 27628-27635, 2008.

[161] L.-F. Chen, W. Fischle, E. Verdin, and W. C. Greene, "Duration of nuclear NF- $\kappa$ B action regulated by reversible acetylation," Science, vol. 293, no. 5535, pp. 1653-1657, 2001.

[162] R. Kiernan, V. Brès, R. W. M. Ng et al., "Post-activation turn-off of NF- $\kappa \mathrm{B}$-dependent transcription is regulated by acetylation of p65," The Journal of Biological Chemistry, vol. 278, no. 4, pp. 2758-2766, 2003.

[163] A. J. Bannister, E. A. Miska, D. Görlich, and T. Kouzarides, "Acetylation of importin- $\alpha$ nuclear import factors by CBP/p300," Current Biology, vol. 10, no. 8, pp. 467-470, 2000.

[164] C. M. Ryan, J. C. Harries, K. B. Kindle, H. M. Collins, and D. M. Heery, "Functional interaction of CREB binding protein (CBP) with nuclear transport proteins and modulation by HDAC inhibitors," Cell Cycle, vol. 5, no. 18, pp. 2146-2152, 2006.

[165] P. Close, C. Creppe, M. Gillard et al., "The emerging role of lysine acetylation of non-nuclear proteins," Cellular and Molecular Life Sciences, vol. 67, no. 8, pp. 1255-1264, 2010.

[166] T. Akoumianaki, D. Kardassis, H. Polioudaki, S. D. Georgattos, and P. A. Theodoropoulos, "Nucleocytoplasmic shuttling of soluble tubulin in mammalian cells," Journal of Cell Science, vol. 122, no. 8, pp. 1111-1118, 2009.

[167] D. Schwartz, M. F. Chou, and G. M. Church, "Predicting protein post-translational modifications using meta-analysis of proteome scale data sets," Molecular and Cellular Proteomics, vol. 8, no. 2, pp. 365-379, 2009.

[168] A. Basu, K. L. Rose, J. Zhang et al., "Proteome-wide prediction of acetylation substrates," Proceedings of the National Academy of Sciences of the United States of America, vol. 106, no. 33, pp. 13785-13790, 2009.

[169] T. Kouzarides, "Acetylation: a regulatory modification to rival phosphorylation," EMBO Journal, vol. 19, no. 6, pp. 1176$1179,2000$. 

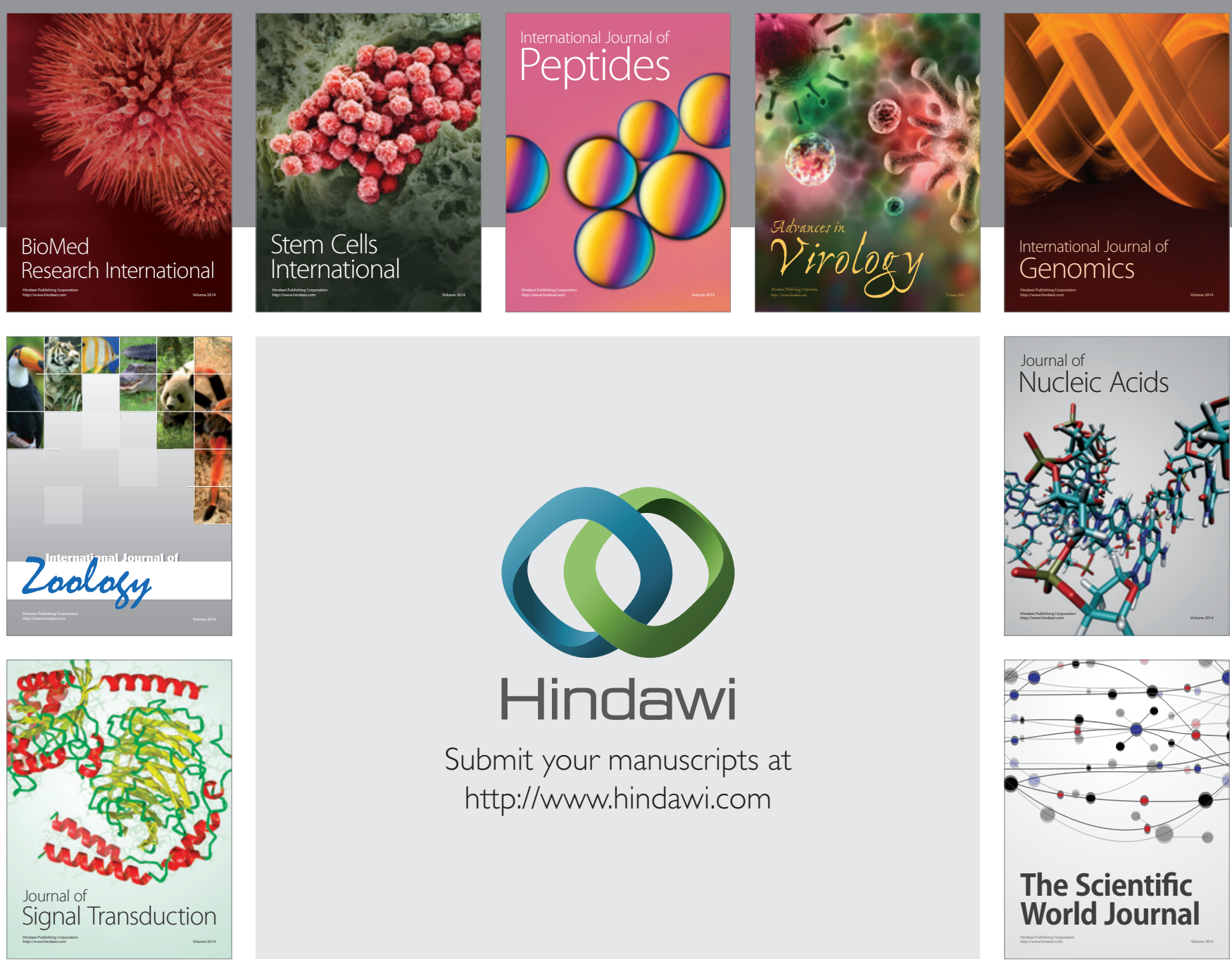

Submit your manuscripts at

http://www.hindawi.com
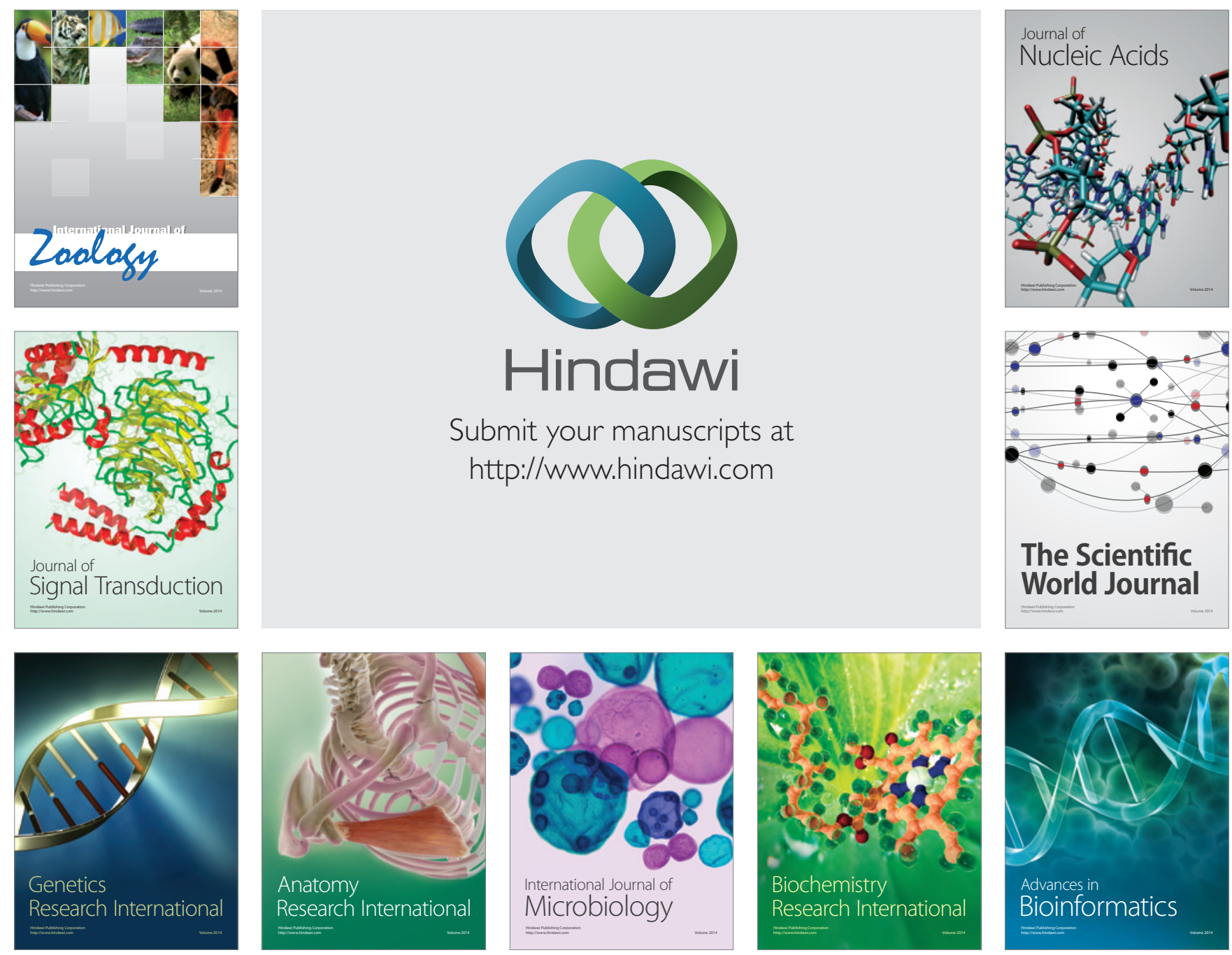

The Scientific World Journal
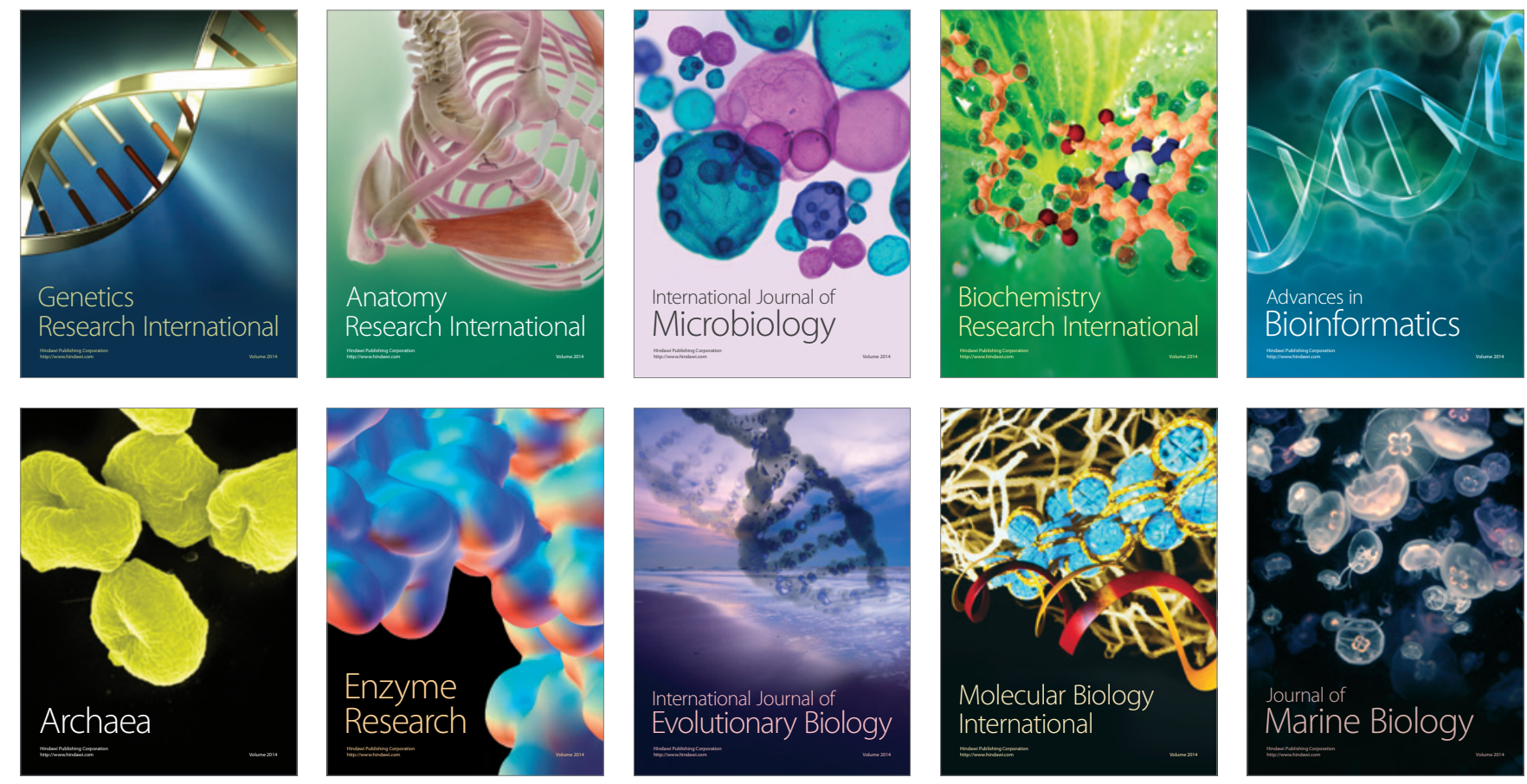